\title{
Regional Distribution of Cortical Interneurons and Development of Inhibitory Tone Are Regulated by Cxcl12/ Cxcr4 Signaling
}

\author{
Guangnan Li, ${ }^{1,2,3}$ Hillel Adesnik, ${ }^{1,4}$ Jennifer Li, ${ }^{1}$ Jason Long, ${ }^{1,3,5}$ Roger A. Nicoll, ${ }^{1,4}$ John L. R. Rubenstein, ${ }^{1,3,5}$ and \\ Samuel J. Pleasure ${ }^{1,2,3}$ \\ Programs in ${ }^{1}$ Neuroscience and ${ }^{2}$ Developmental Biology, and Departments of ${ }^{3}$ Neurology, ${ }^{4}$ Cellular and Molecular Pharmacology, and ${ }^{5}$ Psychiatry, \\ University of California, San Francisco, San Francisco, California 94158
}

\begin{abstract}
Interneurons are born in subcortical germinative zones and tangentially migrate in multiple streams above and below the developing cortex, and then, at the appropriate developmental stage, migrate radially into the cortex. The factors that control the formation of and the timing of exit from the streams remain obscure; moreover, the rationale for this complicated developmental plan is unclear. We show that a chemokine, $\mathrm{Cxcl12}$, is an attractant for interneurons during the stage of stream formation and tangential migration. Furthermore, the timing of exit from the migratory streams accompanies loss of responsiveness to Cxcl12 as an attractant. Mice with mutations in Cxcr4 have disorganized migratory streams and deletion of $\mathrm{Cxcr} 4$ after the streams have formed precipitates premature entry into the cortical plate. In addition, constitutive deletion of Cxcr4 specifically in interneurons alters the regional distribution of interneurons within the cortex and leads to interneuron laminar positioning defects in the postnatal cortex. To examine the role of interneuron distribution on the development of cortical circuitry, we generated mice with focal defects in interneuron distribution and studied the density of postnatal inhibitory innervation in areas with too many and too few interneurons. Interestingly, alterations in IPSC frequency and amplitude in areas with excess interneurons tend toward normalization of inhibitory tone, but in areas with reduced interneuron density this system fails. Thus, the processes controlling interneuron sorting, migration, regional distribution, and laminar positioning can have significant consequences for the development of cortical circuitry and may have important implications for a range of neurodevelopmental disorders.
\end{abstract}

Key words: chemokines; tangential migration; cortex; development; GABA; interneurons

\section{Introduction}

The balance of excitation and inhibition is critical for cortical function; imbalance disrupts closing of critical periods (Hensch, 2005) and sensing and processing information (Wulff and Wisden, 2005), and is associated with a number of human conditions, such as epilepsy (Cossart et al., 2005). Development of the cerebral cortex uses a complex developmental plan that makes the ability to establish the precise balance of inhibition and excitation all the more amazing. Excitatory neurons are generated in the cortex and then migrate radially to adopt laminar positions with an inside-out gradient according to birthdate (for review, see Ayala et al., 2007; Hevner, 2007; Molyneaux et al., 2007). Meanwhile, GABAergic interneurons, generated in subcortical germi-

Received 0ct. 9, 2007; revised Nov. 27, 2007; accepted Dec. 7, 2007.

This work was supported by a research grant from Autism Speaks and National Institute of Mental Health Grants K02 MH074958, R01 MH066084, and R01 MH077694 (S.J.P.); and a research grant from Nina Ireland and National Institute of Mental Health Grants R01 MH49428 and K05 MH065670 (J.L.R.R.). We thank Oscar Marín for communicating unpublished results and other members of the Pleasure and Rubenstein laboratories for helpful suggestions.

Correspondence should be addressed to Samuel J. Pleasure, Department of Neurology, University of California,

San Francisco, Mission Bay, 1550 Fourth Street, Room 448C, Rock Hall, San Francisco, CA 94158. E-mail: sam.pleasure@ucsf.edu.

DOI:10.1523/JNEUROSCI.4602-07.2008

Copyright $\odot 2008$ Society for Neuroscience $\quad$ 0270-6474/08/281085-14\$15.00/0 native zones, migrate tangentially and ultimately sort themselves into the correct layers in the cortex (for review, see Wonders and Anderson, 2005; Metin et al., 2006; Ayala et al., 2007).

Although recent studies have characterized a number of important extracellular regulatory cues that regulate steps in subcortical sorting and tangential migration of interneurons [too numerous to recount in detail here but extensively reviewed by Wonders and Anderson (2005), Metin et al. (2006), and Ayala et al. (2007)], there has been no clear understanding of one of the most prominent features of interneuron migration, their organization into migratory streams and the function of these streams in interneuron distribution. Previous studies showed that mice bearing mutations in the chemokine receptor Cxcr4 or its ligand Cxcl12 [also known as stromal cell-derived factor-1 (SDF-1)] have defects in the positioning of neocortical interneurons during migration both in the superficial and deep migratory streams and Cxcl12 expression by the meninges presumably regulates the localization of interneurons in the marginal zone (MZ) (Stumm et al., 2003). Additional studies showed that meningeal expression of Cxcl12 is crucial for organizing the marginal zone positioning and migration of Cajal-Retzius cells, another prominent MZ resident neuron population (Borrell and Marín, 2006; Paredes et al., 2006). In addition, Cxcl12 expression in the cortical 
subventricular zone (SVZ) and intermediate zone (IZ) is also important for regulating interneuron migration into the cortex (Tiveron et al., 2006). However, none of these studies examined how the expression of this presumed chemoattractant regulates the timing and organization of stream formation and maintenance. In addition, because of the neonatal lethal phenotypes of Cxcl12- and Cxcr4-null mutants, these studies did not examine the postnatal consequences of disruption of Cxcl12/Cxcr4 signaling on interneuron positioning or numbers. Thus, the major question of the consequences of loss of the interneuron migratory streams on the final disposition and function of interneurons has remained unclear, and the more fundamental question of what the function of the migratory streams is in regulating the development of cortical excitability has been completely unexamined.

In this study, we demonstrate that, in addition to acting as an attractant controlling the initial sorting of interneurons into the migratory streams, Cxcl12/Cxcr4 signaling controls the timing of interneuron exit from these streams. In addition, using interneuron-selective Cxcr4 mutants, we find that postnatal interneuron distribution and laminar positioning is affected, and that mice with regional interneuron sorting defects have alterations in the development of cortical excitability.

\section{Materials and Methods}

Animals. The following mouse lines were purchased from The Jackson Laboratory (Bar Harbor, ME): Cxcr4 (stock no. 004341), Z/EG cre reporter line (stock no. 004178), GAD1-green fluorescent protein (GFP) transgenic line (stock no. 003718), and ubiquitous inducible cre line CAG-CreER (stock no. 004682). Lhx6GFP BAC line was obtained from GENSAT (The Gene Expression Nervous System Atlas Project at The Rockefeller University, New York, NY). Cxcr4-flox animals were kindly provided by Dr. Dan Littman (New York University, New York, NY) and the Dlx5/6Cre line was generated in the laboratory of J. L. R. Rubenstein [University of California, San Francisco (UCSF)]. The following breeding schemes were used to obtain littermate controls and mutants: Lhx6$\mathrm{GFP}^{\mathrm{Tg} /+} ; \mathrm{Cxcr}^{+/-} \times \mathrm{Cxcr}^{+/-}{ }^{+ \text {for Lhx6-GFP }}{ }^{\mathrm{Tg} /+} ; \mathrm{Cxcr}^{+/+}$and Lhx6$\left.\mathrm{GFP}^{\mathrm{Tg} /+} ; \mathrm{Cxcr}^{-/-}\right), \mathrm{CAG}-\mathrm{CreER}^{\mathrm{Tg} /+} ; \mathrm{Cxcr}^{+/-} \times \mathrm{Cxcr}^{\text {flox/flox }}$ (for

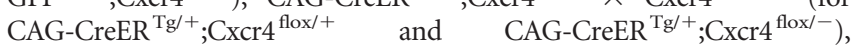

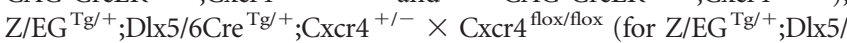
$6 \mathrm{Cre}^{\mathrm{Tg} /+} ; \mathrm{Cxcr} 4^{\text {flox/++}}$ and $\left.\mathrm{Z} / \mathrm{EG}^{\mathrm{Tg} /+} ; \mathrm{Dlx} 5 / 6 \mathrm{Cre}^{\mathrm{Tg} /+} ; \mathrm{Cxcr} 4^{\text {flox/--}}\right)$, Lhx6$\mathrm{GFP}^{\mathrm{Tg} /+} ; \mathrm{Dlx} 5 / 6 \mathrm{Cre}^{\mathrm{Tg} /+} ; \mathrm{Cxcr}^{+/-} \times \mathrm{Cxcr}^{\text {flox/flox }}$ (for Lhx6-GFP ${ }^{\mathrm{Tg} /+}$;

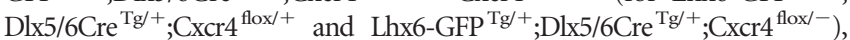
and GAD1-GFP ${ }^{\mathrm{Tg} /+} ; \mathrm{Dlx} 5 / 6 \mathrm{Cre}^{\mathrm{Tg} /+} ; \mathrm{Cxcr}^{+/-} \times \mathrm{Cxcr}^{\text {flox/flox }}$ (for GAD1$\mathrm{GFP}^{\mathrm{Tg} /+} ; \mathrm{Dlx} 5 / 6 \mathrm{Cre}^{\mathrm{Tg} /+} ; \mathrm{Cxcr}^{\text {flox } /+}$ and $\mathrm{GAD}^{-\mathrm{GFP}^{\mathrm{Tg} /+}} ; \mathrm{Dlx} 5 / 6 \mathrm{Cre}^{\mathrm{Tg} /+}$; $\mathrm{Cxcr} 4^{\text {flox } /-}$ ). The day of vaginal plug was considered embryonic day 0.5 (E0.5). Mouse colonies were kept at UCSF in accordance with National Institutes of Health and UCSF guidelines. The Cxcr4-null mice are on a pure C57BL/6 background, but all other lines of mice are on mixed backgrounds between C57BL/6 and CD1. In all cases, controls are littermate and from the same degree of mixed background.

Cortical slice culture and bead analysis. We dissected brains from E13.5 embryos or postnatal day $0(\mathrm{P} 0)$ newborns in ice-cold $1 \times$ Hanks buffer (no. 140-25-076; Invitrogen, Carlsbad, CA). Lhx6-GFP+ brains were selected by direct inspection with a fluorescence dissection microscope. The $250 \mu \mathrm{m}$ coronal cortical sections were prepared by cutting on a Leica (Nussloch, Germany) vibrating microtome. Slices were grown on Millicell-CM (Biopore PICMORG50) in $35 \mathrm{~mm}$ Petri dishes in serumfree medium $(1 \times$ Neurobasal medium, $2 \%$ B-27 supplement, $0.5 \%$ glucose, $1 \%$ penicillin/streptomycin, 2 mm GlutaMAX-1). Slices were allowed to recover for $2-3 \mathrm{~h}$ before any treatment was started. For bead analysis, we soaked agarose beads (Bio-Rad, Hercules, CA) with BSA (10 $\mu \mathrm{g} / \mathrm{ml}$; Sigma, St. Louis, MO) or Cxcl12 (SDF-1 $\alpha)(10 \mu \mathrm{g} / \mathrm{ml} ; \mathrm{R} \& \mathrm{D}$ Systems, Minneapolis, $\mathrm{MN}$ ) at $4^{\circ} \mathrm{C}$ for $1 \mathrm{~h}$ before placing the beads at the appropriate locations in the slices with fine forceps. After culture at $37^{\circ} \mathrm{C}$ with $5 \% \mathrm{CO}_{2}$ for the listed amount of time, confocal pictures were taken for analyzing the chemoattractant effect.

In utero electroporation. Timed pregnant mice at desired ages were anesthetized with sodium pentobarbital at $60 \mathrm{mg} / \mathrm{kg}$ body weight. The abdomen was cleaned with $70 \%$ ethanol. A midline incision was made, and the uterus was exposed. The cerebral vesicle of each embryo was transilluminated with a fiber optic source and DNA solution prepared at $2 \mathrm{mg} / \mathrm{ml}$ in $10 \mathrm{~mm}$ Tris- $\mathrm{HCl}$, $\mathrm{pH}$ 8.0, with $0.04 \%$ trypan blue was injected into lateral ventricle with a glass micropipette. After injection, embryos were held with a forcep-type electrode with two platinum paddles (Protech International, San Antonio, TX). Electrical pulses (42 V for E13.5, 50 $\mathrm{V}$ for E14.5) with $50 \mathrm{~ms}$ duration were delivered five times at $950 \mathrm{~ms}$ intervals using a square-pulse electroporator BTX830. After the procedure, the uterus was replaced into the abdominal cavity, and the abdominal cavity was filled with prewarmed $1 \times$ PBS. The abdominal wall and skin were sutured to allow the embryos to develop further. The mother was placed on a $37^{\circ} \mathrm{C}$ hot plate until recovery from the surgery. The entire surgical procedure was completed within $45 \mathrm{~min}$. The following fulllength cDNAs were cloned into the chicken $\beta$-actin CMV (cytomegalovirus) promoter driven expression vector pCAGGS (provided by J. L. R. Rubenstein): DsRed2 (Clontech, Cambridge, UK), Cxcl12 (IMAGE clone 3984285; Open Biosystems, Huntsville, AL).

Tamoxifen induction. Tamoxifen (Sigma) was dissolved in corn oil (Sigma) at $20 \mathrm{mg} / \mathrm{ml}$. For temporal removal of Cxcr4, pregnant females with embryos at E15.5 were intraperitoneally injected with tamoxifen at $3 \mathrm{mg}$ per $40 \mathrm{~g}$ animal.

Immunohistochemistry. Embryos older than E13.5 and postnatal mice were perfused with $1 \times$ PBS followed by $4 \%$ paraformaldehyde (PFA). Dissected brains were postfixed in 4\% PFA overnight and then cryoprotected in 30\% sucrose until they sank. Brains were frozen and sectioned coronally at $40 \mu \mathrm{m}$ on a cryostat. Floating sections were stained with the following antibodies according to standard protocols: rabbit or mouse anti-GFP (1:1000; Invitrogen), rat anti-CTIP2 (1:1000; Abcam, Cambridge, MA), rabbit anti-calretinin (1:1000; Chemicon, Temecula, CA), rabbit anti-neuronal nitric oxide synthase (nNOS) (1:1000; Zymed, San Francisco, CA), mouse anti-parvalbumin (1:1000; Swant, Bellinzona, Switzerland), mouse anti-calbindin (1:1000; Swant), rabbit anti-NPY (1: 1000; Immunostar, Hudson, WI). Primary antibodies were detected with secondary antibodies (goat anti-rabbit, goat anti-mouse, or goat antirat) conjugated to Alexa fluorochromes (1:1000; Invitrogen).

In situ hybridization. Embryos older than E13 were perfused with $4 \%$ PFA and brains were dissected and postfixed in 4\% PFA for $4 \mathrm{~h}$ (for E13.5-E15.5 brains) or overnight (for brains older than E15.5). Fixed brains were cryoprotected in $30 \%$ sucrose before embedding in OCT. Brain tissues were cut on a cryostat at $20 \mu \mathrm{m}$ and directly mounted onto Superfrost slides (Fisher Scientific, Houston, TX). All the slides were stored at $-80^{\circ} \mathrm{C}$ before use. For in situ hybridization (ISH), slides were warmed to $55^{\circ} \mathrm{C}$, fixed in $4 \%$ PFA for $30 \mathrm{~min}$, treated with proteinase $\mathrm{K}$ $(50 \mathrm{mg} / \mathrm{ml})$ for $1.5 \mathrm{~min}$, and fixed again with $4 \%$ PFA for $30 \mathrm{~min}$. Acetylation was performed using $0.25 \%$ acetic anhydride in $0.1 \mathrm{M}$ triethanolamine, $\mathrm{pH}$ 8.0, for $10 \mathrm{~min}$, followed by three PBS washes. Slides were incubated with hybridization buffer [ $50 \%$ formamide, $5 \times$ SSC, 0.3 $\mathrm{mg} / \mathrm{ml}$ yeast tRNA, $100 \mathrm{mg} / \mathrm{ml}$ heparin, $1 \times$ Denhart's, $0.1 \%$ Tween 20 , 0.1\% CHAPS (3-[(3-cholamidopropyl)dimethylammonio]-1-propanesulfonate), $5 \mathrm{~mm}$ EDTA] for $30 \mathrm{~min}$ at $65^{\circ} \mathrm{C}$, followed by overnight incubation with a digoxigenin-labeled probe. Three high-stringency washes were performed with $0.2 \times \mathrm{SSC}$ at $65^{\circ} \mathrm{C}$. Slides were then incubated with horseradish alkaline phosphatase (AP)-conjugated anti-digoxigenin and NBT (nitroblue tetrazolium)/BCIP (5-bromo-4-chloro-indolyl phosphate) for signal detection. The probes and their sources were as follows: Cxcl12 (IMAGE clone 3984285) and Cxcr4 (IMAGE clone 3592479; Open Biosystems), and Lhx6 and GAD67 (provided by J. L. R. Rubenstein).

Image analysis and quantification. Images were acquired using a cooled-CCD camera (QCapture Pro; QImaging, Burnaby, British Columbia, Canada). To quantitate the distribution of the recombined interneurons, counting boxes of equal size in controls $\left(\mathrm{Z} / \mathrm{EG}^{\mathrm{Tg} /+} ; \mathrm{Dlx} 5 /\right.$

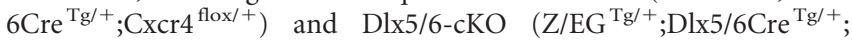
$\mathrm{Cxcr} 4^{\text {flox/- }}$ ) animals were drawn in cingulate cortex, motor cortex, and somatosensory cortex at the bregma level of $-0.94 \mathrm{~mm}$. Six pairs of animals were analyzed. The numbers of GFP + cells were normalized with the average values of the corresponding regions in the controls. For 
Lhx6-GFP + animals with in utero electroporation of pCAG-DsRed2 alone, or together with pCAG-Cxcl12 targeted into the somatosensory cortex, counting boxes of the same size were drawn in somatosensory cortex or cingulated cortex in the electroporated sides and contralateral sides. The ratio was calculated as the number of Lhx6GFP + cells in the electroporated side divided by the number of Lhx6GFP + cells in the contralateral side within the corresponding counting boxes. To further analyze the laminar distribution of Lhx6-GFP+ cells in the somatosensory cortices of the electroporated animals, a grid of 10 equal horizontal bins were drawn in the counting boxes. Bin 1 approximately corresponds to the marginal zone and bin 10 to the lower end of layer VI. The data were presented as the percentage of the total number within the boxes.

The results were expressed as the mean \pm SEM for $n$ given samples. Data were analyzed using two-tailed Student's $t$ test with unequal variance. Any value of $p \leq 0.05$ was considered significant.

Electrophysiology. Coronal brain slices (300 $\mu \mathrm{m}$ thick) were cut from 2to 3-week-old mice on a Leica vibrating microtome in normal ice-cold artificial CSF. After 1-2 h of incubation at room temperature, slices were transferred to a submersion chamber on an upright Olympus (Tokyo, Japan) BX51 microscope, and layer 4 pyramidal cells in somatosensory "barrel," or in a medial region (cingulate cortex), were visualized by infrared-differential interference contrast optics. The electroporated region of the slice was visualized by epifluorescence, and cells were targeted within the confines of the transfected area or in the equivalent region from the contralateral side. The extracellular solution contained the following (in mM): $119 \mathrm{NaCl}, 2.5 \mathrm{KCl}, 26 \mathrm{NaHCO}_{3}, 1 \mathrm{Na}_{2} \mathrm{PO}_{4}, 11$ glucose, $2.5 \mathrm{CaCl}_{2}$, and $1.3 \mathrm{MgCl}_{2}$, and saturated with $95 \% \mathrm{O}_{2} / 5 \% \mathrm{CO}_{2}$. The intracellular solution contained the following (in mM): $135 \mathrm{CsMeSO}_{4}, 8$ $\mathrm{NaCl}, 10$ HEPES, $0.3 \mathrm{Na}_{3} \mathrm{GTP}, 4 \mathrm{MgATP}, 0.3$ EGTA, and 5 QX-314 (lidocaine $\mathrm{N}$-ethyl bromide). Experiments in which series resistance changed by $>20 \%$ were excluded from analysis. Spontaneous IPSCs were collected at a holding potential of $0 \mathrm{mV}$. Under our conditions, the GABA reversal potential was approximately $-45 \mathrm{mV}$, and thus the IPSCs were recorded as outward currents. Spontaneous events (75-125) were collected per cell and semiautomatically detected by in-house software in Igor Pro (WaveMetrics, Lake Oswego, OR). The Kolmogorov-Smirnov test was used to obtain $p$ values for the analysis of cumulative distributions.

\section{Results \\ Interneuron migration is organized into characteristic stages during prenatal life}

During neocortical and hippocampal development in mice, most interneurons are generated from the germinal zones in the subpallium, including the medial ganglionic eminence (MGE). MGE-derived interneurons can be identified by the expression of a LIM-homeobox gene Lhx6, which plays a critical role in the fate determination and migration of the cells originated from MGE (Alifragis et al., 2004; Liodis et al., 2007). The tangential migration of these cells from the MGE to the cortex form two streams that are visualized in transgenic mice expressing GFP driven by the Lhx6 promoter (Cobos et al., 2006) (supplemental Fig. 1A, available at www.jneurosci.org as supplemental material). A superficial stream is in the MZ, and a deep stream is in the SVZ and IZ.

Lhx6-GFP expression reveals the dynamic nature of interneuron migration and stream organization during embryonic and early postnatal life is delineated by the Lhx6-GFP expression. At E13.5, GFP + cells course through the SVZ of the lateral ganglionic eminence (LGE) and the LGE/cortex border, at which point one can readily distinguish the two prominent cortical migratory streams (Fig. 1A). Lhx6-GFP + cells progressively accumulate in the $\mathrm{MZ}$ over the next $2 \mathrm{~d}$ [supplemental Fig. $1 B, C$, arrows (available at www.jneurosci.org as supplemental material)]. Cells with shapes suggesting that they are migrating (extended morphology with a clear leading process) are abundant in the IZ/SVZ; a few are also seen in the cortical plate. Most cells with migratory morphology are oriented with their leading processes toward the medial cortex indicating migration medially [supplemental Fig. $1 B$, red arrowheads (available at www.jneurosci.org as supplemental material)], although small numbers of cells are seen with their leading process oriented either laterally or radially [supplemental Fig. $1 B$, yellow arrowheads (available at www.jneurosci.org as supplemental material)]. This is consistent with previous studies demonstrating that the superficial and deep interneuron streams have some exchange as well as the tendency of many interneurons to migrate in a variety of directions within local zones (Ang et al., 2003; Tanaka et al., 2003; Yokota et al., 2007).

At E17.5, there continue to be large numbers of GFP + cells in the MZ [supplemental Fig. 1C, white arrows (available at www. jneurosci.org as supplemental material)], whereas the number of cells in deeper layers has decreased; most cells in the IZ and cortical plate do not have migratory morphology [supplemental Fig. $1 C$ (available at www.jneurosci.org as supplemental material)]. The exception to this is in the SVZ, where there is a stream of apparently migrating GFP + cells [supplemental Fig. $1 C$, white arrowheads (available at www.jneurosci.org as supplemental material)]. By E18.5, the MZ begins to be depleted of GFP + cells [supplemental Fig. $1 D$, arrows (available at www.jneurosci.org as supplemental material)]. Within the cortical plate, most GFP+ cells are radially oriented with a bipolar morphology, suggesting that they engaged in radial migration, perhaps from the MZ. Over the next $3 \mathrm{~d}$, the MZ (layer 1 of the cortex) becomes depleted of $\mathrm{GFP}+$ cells [supplemental Fig. 1E, arrows (available at www. jneurosci.org as supplemental material)], whereas deeper cortical layers have large numbers of GFP + cells that are beginning to extend processes [supplemental Fig. $1 E$ (available at www.jneurosci.org as supplemental material)]. Thus, from E13.5 to E17.5, the MZ accumulates GFP+ interneurons (supplemental Fig. $1 B, C$, arrows), and from E17.5 to P2, the number of these cells decreases [supplemental Fig. 1D,E, arrows (available at www. jneurosci.org as supplemental material)]. In the SVZ stream, the number of GFP + cells increases from E13.5 to E15.5, and subsequently decreases [supplemental Fig. $1 B-E$, white arrowheads (available at www.jneurosci.org as supplemental material)]. These dynamic changes in the distributions of Lhx6-GFP + cells are consistent with the observations of others using different labeling approaches (Ang et al., 2003; Tanaka et al., 2003; Yokota et al., 2007) and provide an anatomical and temporal framework for assessing the mechanisms that regulate the tangential and radial migration of these immature interneurons.

\section{Spatial and temporal regulation of Cxcl12 and Cxcr4 expression in the developing forebrain}

Previous studies suggested that $\mathrm{Cxcl} 12$ and $\mathrm{Cxcr} 4$ are involved in regulating cortical interneuron migration (Stumm et al., 2003; Tiveron et al., 2006), but none of these studies provided insights into the cellular mechanisms governing how Cxcl12/Cxcr4 signaling regulates migration in the setting of the dynamic nature of the migratory stages described above.

At early stages of corticogenesis (E13.5), when the interneuron streams are forming, Cxcl12 is expressed prominently by the meninges overlying the telencephalon [supplemental Fig. $2 \mathrm{~A}$, black arrows (available at www.jneurosci.org as supplemental material)] and within the cortex in a ventral-to-dorsal gradient in the SVZ [supplemental Fig. $2 \mathrm{~A}$, black arrowheads (available at www.jneurosci.org as supplemental material)] and weakly by the lateral cortical plate [supplemental Fig. $2 A, B$, blue arrowheads 
(available at www.jneurosci.org as supplemental material)]. Cxcl12 RNA expression is more intense in the meninges than in the cortex at E13.5 and E16.5 [supplemental Fig. $2 B$ (available at www.jneurosci.org as supplemental material)]. The temporal and spatial expression of Cxcl12 in the meninges and the cortex suggests that it contributes to organizing the interneurons into superficial and deep streams. Furthermore, the ventral-to-dorsal gradients within the cortical SVZ and cortical plate, may regulate their tangential dispersion. In contrast, as has been reported in detail by others (Stumm et al., 2003, 2007; Tissir et al., 2004; Daniel et al., 2005), the Cxcl12 receptor Cxcr4 is weakly expressed in the migrating interneurons entering the cortex at both E13.5 and E16.5 [supplemental Fig. $2 D, E, G$, arrowheads (available at www. jneurosci.org as supplemental material)], whereas it is highly expressed in the CajalRetzius cells in MZ [supplemental Fig. $2 C-G$, arrows (available at www. jneurosci.org as supplemental material)]. The distribution pattern of $\mathrm{Cxcl} 12$ in the meninges and SVZ suggests that it may play a role in organizing interneurons into streams, whereas the tapering pattern of Cxcl12 in the SVZ may facilitate the lateralto-medial dispersion of interneuron. Moreover, the spatial gradient (high in meninges to low in SVZ) and the temporal gradient (low at E13.5 to high at E16.5) of Cxcl12 suggest it may play a critical role in the $\mathrm{MZ}$ accumulation of interneurons in that particular time window.

\section{Cxcl12 is only a chemoattractant for Lhx6-GFP+ interneurons at embryonic stages}

The expression of Cxcl12 along the SVZ and meninges suggests that it may act as an attractant to focus interneurons into deep and superficial streams, respectively, and to promote interneuron accumulation in the $\mathrm{MZ}$ from E13 to E17. To test this idea, we implanted beads soaked in Cxcl12 or BSA into the MGE, LGE, or cortex of E13.5 cultured slices prepared from Lhx6-GFP transgenic mice; only the Cxcl12 beads attracted a penumbra of GFP + cells (Fig. 1, 1, 2, 3, 4; $n=6$ of 6). Thus, Cxcl12 is able to act as a chemoattractant for Lhx6-GFP+ interneurons at various stages in their migration, including as they sort into streams.

Lhx6-GFP + cells in the MZ appear to radially migrate into the cortical plate from E18.5 through P2 (supplemental Fig. 1, available at www.jneurosci.org as supplemental material). Because Cxcl12 continues to be expressed in the meninges during that time window (Stumm et al., 2003, 2007), it raises the issue of how the GFP + cells adjust their responsiveness to Cxcl12 during this period; either the GFP + cells change their responsiveness (losing their attractive response or becoming repulsed by $\mathrm{Cxcl12}$ ), or the
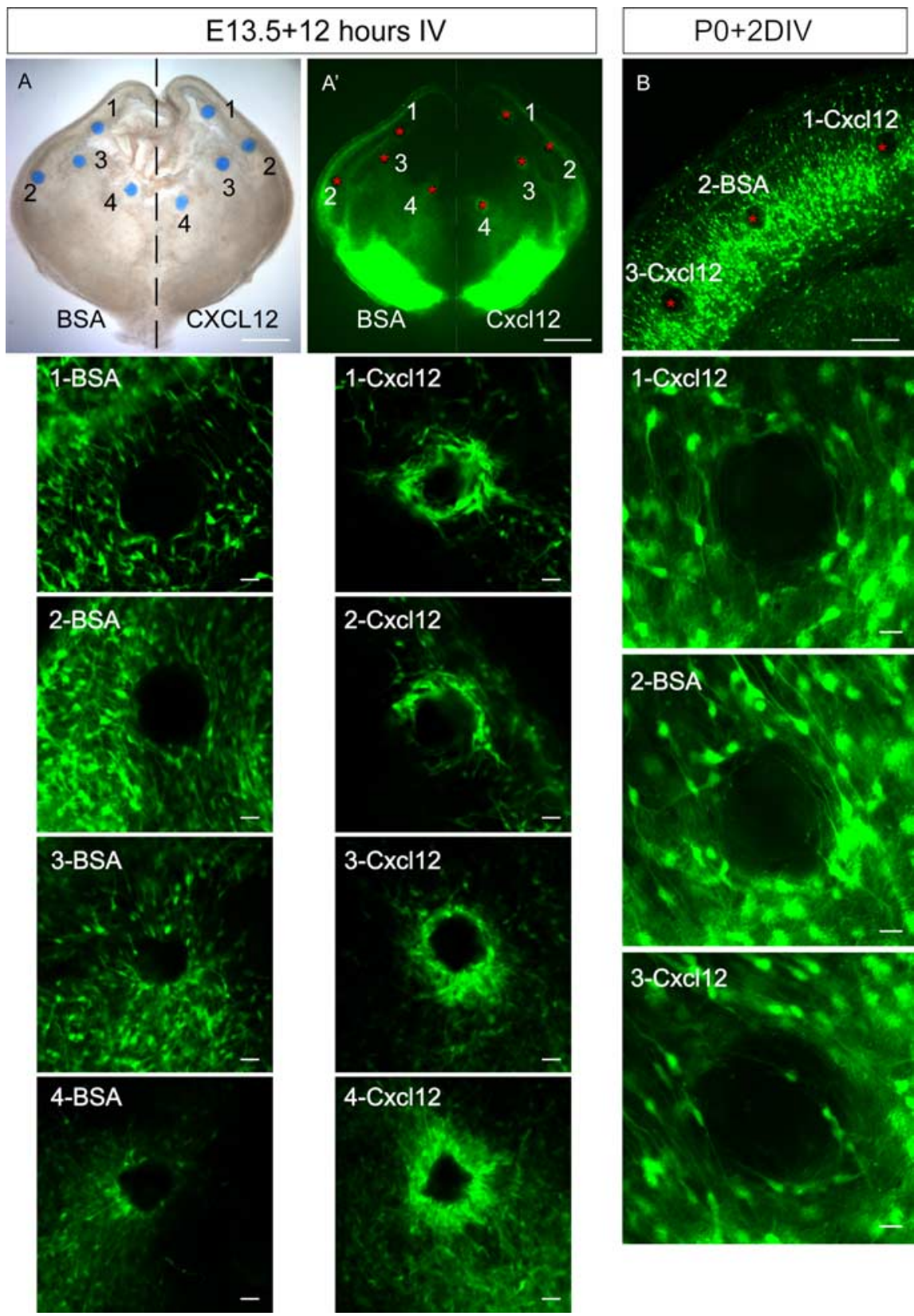

Figure 1. Dynamic changes of interneuron responsiveness to $\mathrm{Cxcl} 12$ in slice cultures. $\boldsymbol{A}, \boldsymbol{A}^{\prime}$, Beads soaked with BSA or re-combinant $\mathrm{CxCl} 12$ were placed on the slices prepared from E13.5 Lhx6-GFP-positive embryos and then cultured for $12 \mathrm{~h}$. $\boldsymbol{A}$ shows the light image, and $\boldsymbol{A}^{\prime}$ shows the confocal image. The positions of the beads in the confocal image are indicated with red asterisks, and they are numbered according to their different locations (1, cortex; 2, cortical entrance; 3, LGE; 4, MGE). To facilitate side-to-side comparisons, the responsiveness of the Lhx6-GFP + interneurons to the ectopic BSA beads on one side or Cxcl12 beads on the other side were performed in the same slices. Lhx6-GFP + cells apparently ignored the BSA beads at all the selected sites but clustered around the $\mathrm{CxCl} 12$ beads (see higher-magnification images arrayed below and numbered as above). $B, A t P 0$, as the interneurons migrated radially, GFP + cells in the cortical plate apparently lost their responsiveness to both BSA and Cxcl12 even after culture for $2 \mathrm{~d}$. Scale bars: $\boldsymbol{A}, \boldsymbol{A}^{\prime}, 500 \mu \mathrm{m} ; \boldsymbol{B}, 125 \mu \mathrm{m}$; all high-power images, $25 \mu \mathrm{m}$.

cues that drive the radial migration are dominant over Cxcl12. To address this, we examined $\mathrm{Cxcl} 12$ responsiveness during this time period by placing Cxcl12-soaked beads into the cortical plate of P0 cultured slices. The GFP + cells did not form a penumbra around the Cxcl12-soaked beads (Fig. 1) ( $n=4$ of 4 ), supporting a model that GFP + cells leave the MZ when they lose their attraction to Cxcl12. Because cells in the cortical plate appeared to ignore Cxcl12, being neither attracted nor repulsed, it does not appear that emigration from the $\mathrm{MZ}$ is attributable to a change in 


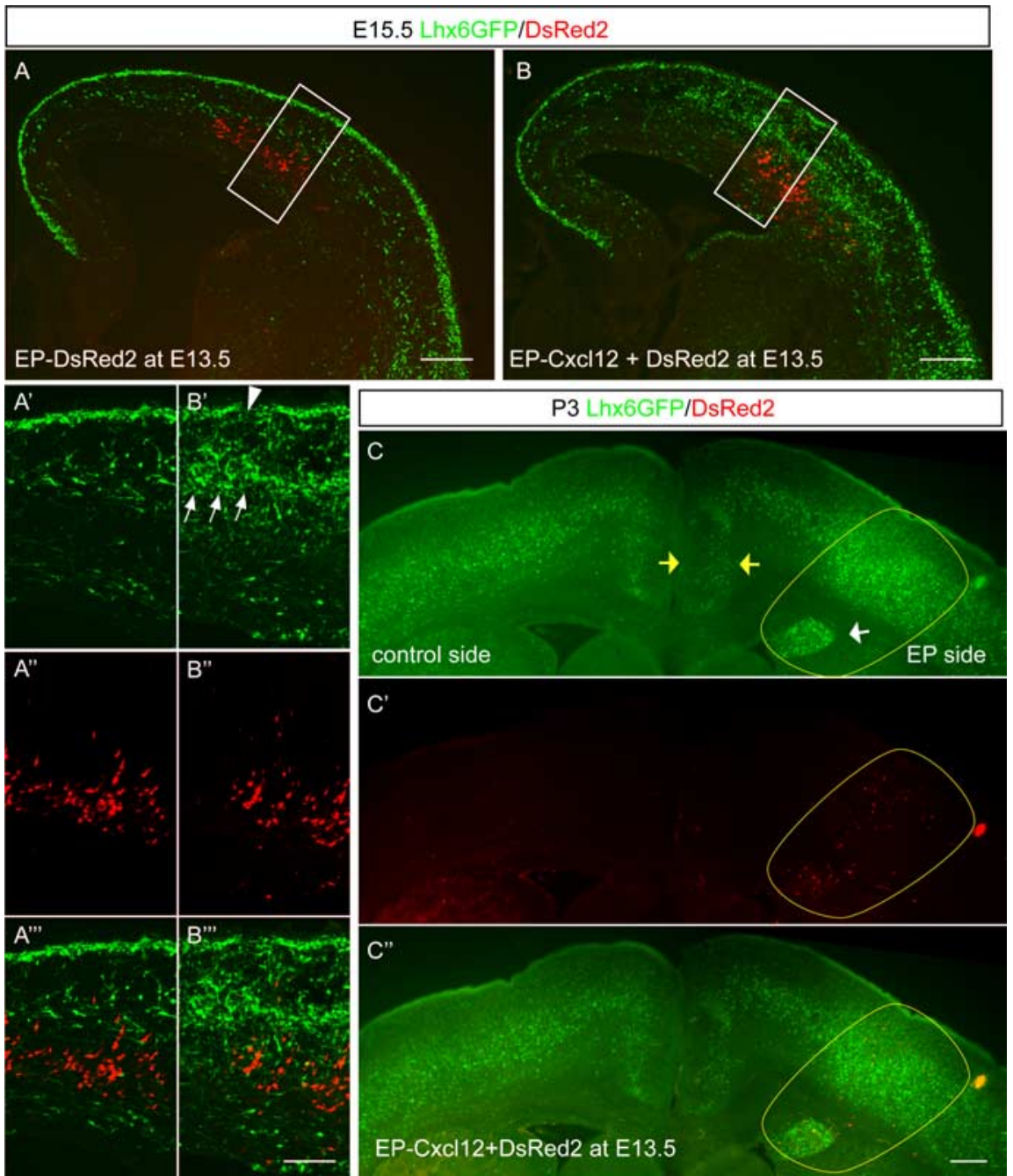

Figure 2. Ectopic Cxcl12 expression causes interneuron accumulation in vivo. $\boldsymbol{A}, \boldsymbol{B}$, Distribution of Lhx6-GFP + cells at E15.5 was examined after in utero electroporation into the lateral cortex at E13.5 with either pCAG-DsRed2 alone $(\boldsymbol{A})$ or together with pCAG-Cxc12 (B). Ectopic Cxc112 expression causes Lhx6-GFP + cell accumulation, whereas DsRed2 expression has no apparent effect. $A^{\prime}$ and $\boldsymbol{B}^{\prime}$ show the distribution of Lhx6-GFP + cells at higher magnification. $\boldsymbol{A}^{\prime \prime}$ and $\boldsymbol{B}^{\prime \prime}$ show the distribution of DsRed2+ cells. $A^{\prime \prime \prime}$ and $\boldsymbol{B}^{\prime \prime \prime}$ 's show the merged images. Scale bars: $A, B, 200 \mu \mathrm{m} ; \boldsymbol{A}^{\prime}-\boldsymbol{A}^{\prime \prime \prime}, \boldsymbol{B}^{\prime}-\boldsymbol{B}^{\prime \prime \prime}, 100 \mu \mathrm{m}$. $C-\boldsymbol{C}^{\prime \prime}$, Distribution of Lhx6-GFP+

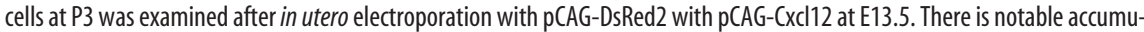
lation of GFP + cells around the ectopic site of expression of (xcl12 (yellow oval) and a decrease in cell number in the medial cortex on the electroporated side (yellow arrows). Note as well that, where there was a small area of ectopic (xcl12 expression in the SVZ (white arrow), there was a focal collection of GFP + cells trapped in this area. EP, Electroporated. Scale bar, $300 \mu \mathrm{m}$.

polarity of Cxcl12 chemotactic activity from attraction to repulsion.

\section{Ectopic Cxcl12 expression interrupts dorsal dispersion of interneurons in vivo}

The bead studies establish that Cxcl12 acts as a chemoattractant in telencephalic slice cultures. Next, we examined whether Cxcl12 acts similarly in vivo using in utero electroporation of a Cxcl12 expression vector into the lateral neocortical ventricular zone (VZ) at E13.5. We examined interneuron distribution after $2 \mathrm{~d}$ (at E15.5) by comparing the distribution of the Lhx6-GFP+ cells on the hemisphere electroporated with Cxcl12 with the nonelectroporated contralateral hemisphere or with hemispheres electroporated with DsRed2 without Cxcl12 (consistent results were obtained in all Cxcl12 electroporated hemispheres regarding disturbance of interneuron distribution; $n>5$ for both Cxcl12 and control DsRed2 electroporations). Ectopic Cxcl12 expression induced collections of Lhx6$\mathrm{GFP}+$ interneurons around the ectopic Cxcl12 (Fig. 2 $B^{\prime}$, arrows). Lhx6-GFP+ cells appeared to be depleted in the $\mathrm{MZ}$ superficial to the zone of ectopic Cxcl12 (Fig. $2 B^{\prime}$, arrowhead); we speculate that the ectopic GFP + cells radially migrated toward the ectopic focus of $\mathrm{Cxcl} 12$ expression (thus depleting the MZ) or were ensnared as they migrated past in the IZ or SVZ.

To determine whether the ectopic Cxcl12 had long-term consequences on interneuron distribution, we examined the mice after longer survival periods after electroporation. When electroporated with Cxcl12 at E13.5 and examined at P3, the areas with ectopic Cxcl12 had dramatic excesses of GFP + cells (Fig. 2C, yellow oval), whereas the number of cells that successfully migrated past the ectopic Cxcl12 source to adopt positions in the dorsal (medial) cortex was decreased (area between the yellow arrows in Fig. 2C). Thus, CXCL12 is a potent chemoattractant for interneurons in vivo, and it is sufficient when overexpressed to trap interneurons en route to their final destinations.

\section{Cxcr4 mutants have defects in organization of immature interneurons into streams}

Because in vitro and in vivo analyses show that Cxcl12 is a chemoattractant for Lhx6GFP + cells, we wanted to determine whether Cxcr4 is required for interneuron stream formation and sorting during development using the Lhx6-GFP transgene as a reporter in Cxcr4 mutant mice. At E13.5, the mutant GFP + cells accumulated external to the striatum in the ventral pallium (anlagen of the claustrum and endopiriform nucleus), olfactory cortex, and perhaps ventral parts of the neocortex (insular cortex anlage) (Fig. 3B' $)$. The mutant interneurons correctly avoided the striatum, which could be identified as CTIP2+ domain (Arlotta et al., 2005) (Fig. $3 A^{\prime}, B^{\prime}$ ), consistent with evidence that semaphorin-based repulsion mediates interneuron avoidance of the striatum (Marín et al., 2001).

The ectopic collection of interneurons in the ventral pallium and olfactory cortex is continuous dorsally with the subplate in the ventrolateral neocortex (Fig. $3 B, C, B^{\prime}, C^{\prime}$, white arrowheads). In control brains, the small number of GFP + cells in the subplate of the lateral cortex apparently joins the SVZ or MZ streams (Fig. $3 C$, white arrowheads), whereas in the mutant brains many of these cells appear to be trapped in the subplate (Fig. $3 C^{\prime}$, white arrowheads). Thus, in controls, the SVZ and MZ (white arrows) streams are well defined as soon as GFP + cells have moved dorsally past the pallial-subpallial boundary (Fig. 3C), whereas in the Cxcr4 mutants the streams are poorly formed leading to gaps in the MZ (white arrows), the poorly organized SVZ stream, and the appearance of ectopic GFP + cells in the VZ (Fig. 3C', yellow arrowheads). This phenotype becomes more severe in dorsal 

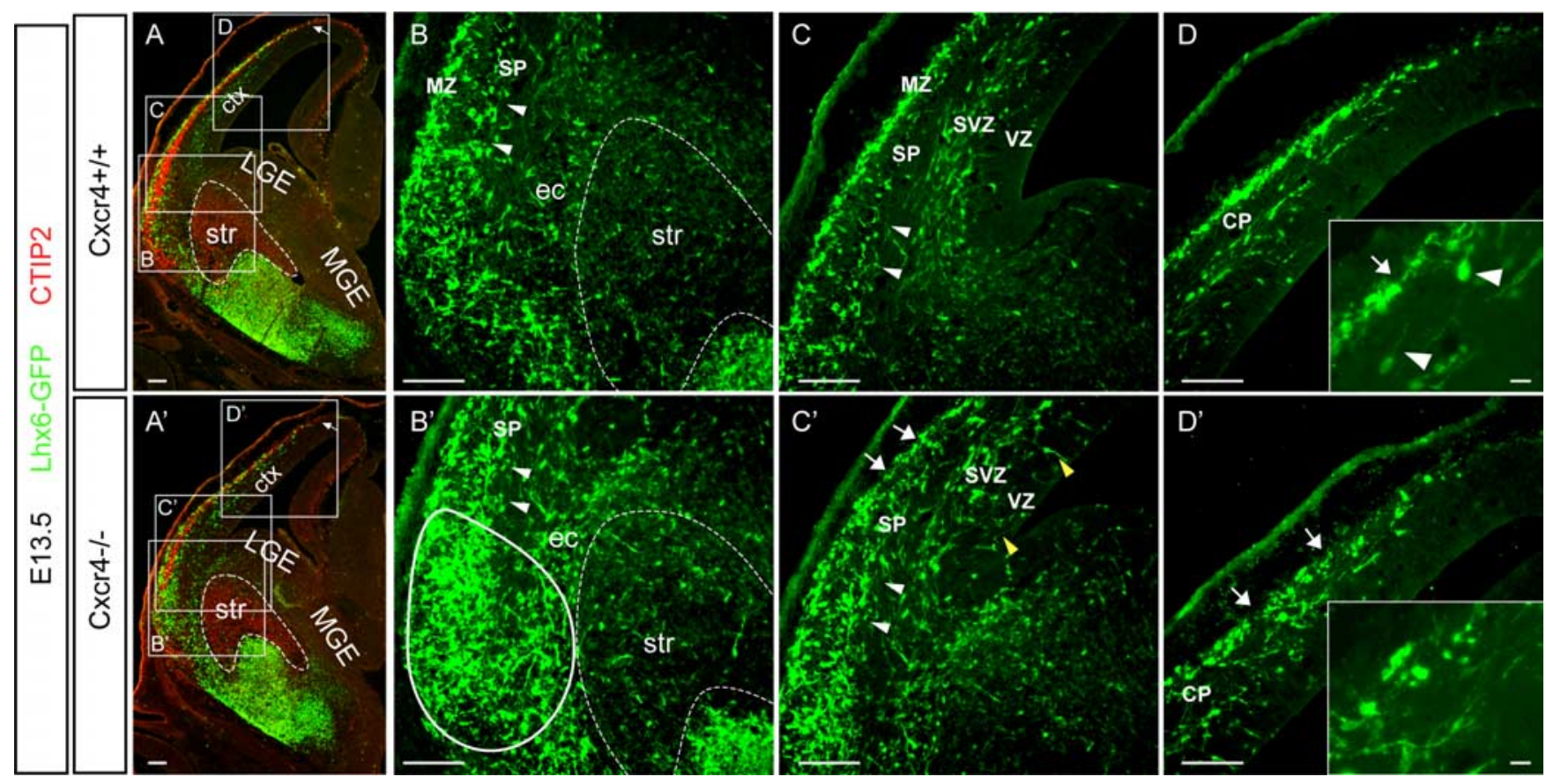

Figure 3. Interneuron sorting is disrupted in Cxcr4 mutants at early stages of stream migration. $\mathrm{CxCr} 4^{+/+}(\boldsymbol{A})$ and $\mathrm{Cxcr} 4^{-/-}\left(\boldsymbol{A}^{\prime}\right)$ brains from E13.5 embryos combined with a single allele of the Lhx6-GFP transgene were stained with antibodies to GFP (green) to label MGE-derived Lhx6-GFP + interneurons and CTIP2 (red) to label the striatum and the forming cortical plate. The arrows in $\boldsymbol{A}$ and $\boldsymbol{A}^{\prime}$ show that the fronts of the migrating interneurons reach almost the same lateral-to-medial level in both controls and mutants. The boxed areas in $\boldsymbol{A}$ and $\boldsymbol{A}^{\prime}$ are shown in $\boldsymbol{B}-\boldsymbol{D}$ and $\boldsymbol{B}^{\prime}-\boldsymbol{D}^{\prime}$, respectively, at higher magnification (and without the red channel). $\boldsymbol{B}, \ln \mathrm{CxCr} 4^{+/+}$brains, MGE-derived Lhx6-GFP + cells migrate superficially to the striatum and organize the beginnings of the MZ stream (MZ) and a minor stream in the subplate (SP) (white arrowheads). Note that this is an area of strong Cxcl12 expression in the MZ and weaker expression in the cortical plate and subplate (see Fig. 2). $\boldsymbol{B}^{\prime}$, In contrast, in (xcr4 ${ }^{-1-}$ brains, Lhx6-GFP + cells form abnormal accumulations in the external capsule (ec), the subplate stream (white arrowheads) is more prominent, and there is an extensive collection of GFP + cells spanning the subplate, forming cortical plate and MZ (solid white oval adjacent to the striatum). C, Slightly more dorsally in Cxcr ${ }^{+/+}$brains, the two fairly defined streams (MZ and SVZ) are sorted and the cells in the subplate stream (white arrowheads) join one of the other of these as cells head into the cortex. Note the paucity of cells between the MZ and SVZ streams and in the VZ. $C^{\prime}$, In $\mathrm{XxCr}^{-1-}$ brains, the subplate stream persists (white arrowheads), there are gaps in the MZ (white arrows), and there are ectopic cells in the VZ (yellow arrowheads). $\boldsymbol{D}$, Once the streams have reached the cortex, the organization is well maintained in Cxcr4 ${ }^{+/+}$mice; where cells are in the cortical plate (CP), they are generally oriented to imply that they are migrating from the SVZ stream to the MZ stream (see inset and white arrowheads). $D^{\prime}, \operatorname{In} C x \mathrm{Cr}^{-1-}$ brains, the stream organization is disrupted with many cells within the CP that do not have morphologies consistent with apparent tangential migration (see inset) and gaps in the MZ. Scale bars: $\boldsymbol{A}-\boldsymbol{D}, \boldsymbol{A}^{\prime}-\boldsymbol{D}^{\prime}, 100 \mu \mathrm{m} ; \boldsymbol{D}, \boldsymbol{D}^{\prime}$, insets, $10 \mu \mathrm{m}$.

parts of the cortex (Fig. 3D, $D^{\prime}$ ). Examining the morphology of the small numbers of GFP + cells in the cortical plate in control cortex shows that these cells generally have a leading process oriented toward the MZ indicating that they may be radially translocating from the SVZ to the MZ (Fig. 3D, inset). In contrast, many mutant GFP + cells in the cortical plate lack a radial orientation (Fig. $3 D^{\prime}$, inset). Thus, the MZ and SVZ streams in Cxcr4 mutants are poorly organized, and many Lhx6-GFP + cells appear to prematurely reside in the cortical plate.

\section{Cxcr4-dependent accumulation of interneurons in the MZ}

As suggested by Lhx6-GFP+ expression and previous studies (Ang et al., 2003; Tanaka et al., 2003; Yokota et al., 2007), immature interneurons accumulate in the MZ over several days (supplemental Fig. 1, available at www.jneurosci.org as supplemental material). At higher magnification, the MZ Lhx6-GFP+ interneurons are approximately one to two cells thick at E14.5 (Fig. $4 D$ ). This increases to two to three cells in thickness at E15.5 (Fig. $4 E$ ) and reaches four to five cells by E16.5 (Fig. $4 F$ ). To determine whether Cxcr4 regulates this process, we examined Cxcr4 mutants carrying the Lhx6-GFP transgene from E14.5 to E16.5. It is apparent that dramatically fewer mutant GFP + cells concentrate in the MZ during this interval (Fig. 4, compare $A-F, A^{\prime}-F^{\prime}$ ). In mutants over this interval, gaps are commonly seen in the MZ (Fig. $4 G^{\prime}$, arrow) and the cortical plate is filled with cells that do not have a clear migratory morphology (Fig. $4 G^{\prime}$, red arrowheads). In control mice at E15.5, many GFP+ cells in the cortical plate still have morphologies consistent with migration toward the MZ (Fig. $4 E$, arrowheads), but not in the mutants (Fig. $4 E^{\prime}$ ) where more and more cells appear stalled in the cortical plate and IZ (Fig. 4E'). Therefore, it appears that concentration of Lhx6$\mathrm{GFP}+$ in the MZ relies on the presence of functional Cxcr4 and presumably on the expression (and increased expression of Cxcl12 over this same time frame) (supplemental Fig. 2, available at www.jneurosci.org as supplemental material) of Cxcl12 in the meninges. Continuing these observations for another day to E16.5, reveals additional accumulation of GFP + cells in the MZ of controls (Fig. $4 F$ ), and a distinct layer of GFP+ cells without apparent migratory morphology begins to appear in the subplate (Fig. $4 F$, arrows). In contrast, the MZ in the mutants is actually becoming depleted of GFP + cells (Fig. $4 F^{\prime}$ ) with many of these apparently migrating radially into the cortical plate (Fig. $4 F^{\prime}$, arrowheads). So, a simple model is that Cxcl12 in the meninges is maintaining the laminar positions of MZ cells and Cxcl12 in the SVZ is holding the SVZ/IZ cells, until the cells are no longer attracted to Cxcl12. Without Cxcr4, cells in the superficial and deep migratory streams precociously move into the cortical plate.

Time-dependent loss of Cxcr4 from MZ interneurons induces early invasion into the cortical plate

Our bead analysis with P0 slices shows that Lhx6-GFP+ cells in the cortical plate are no longer responsive to the Cxcl12-soaked beads, and this seems to coincide approximately with the time that interneurons migrate radially into the cortex away from the 


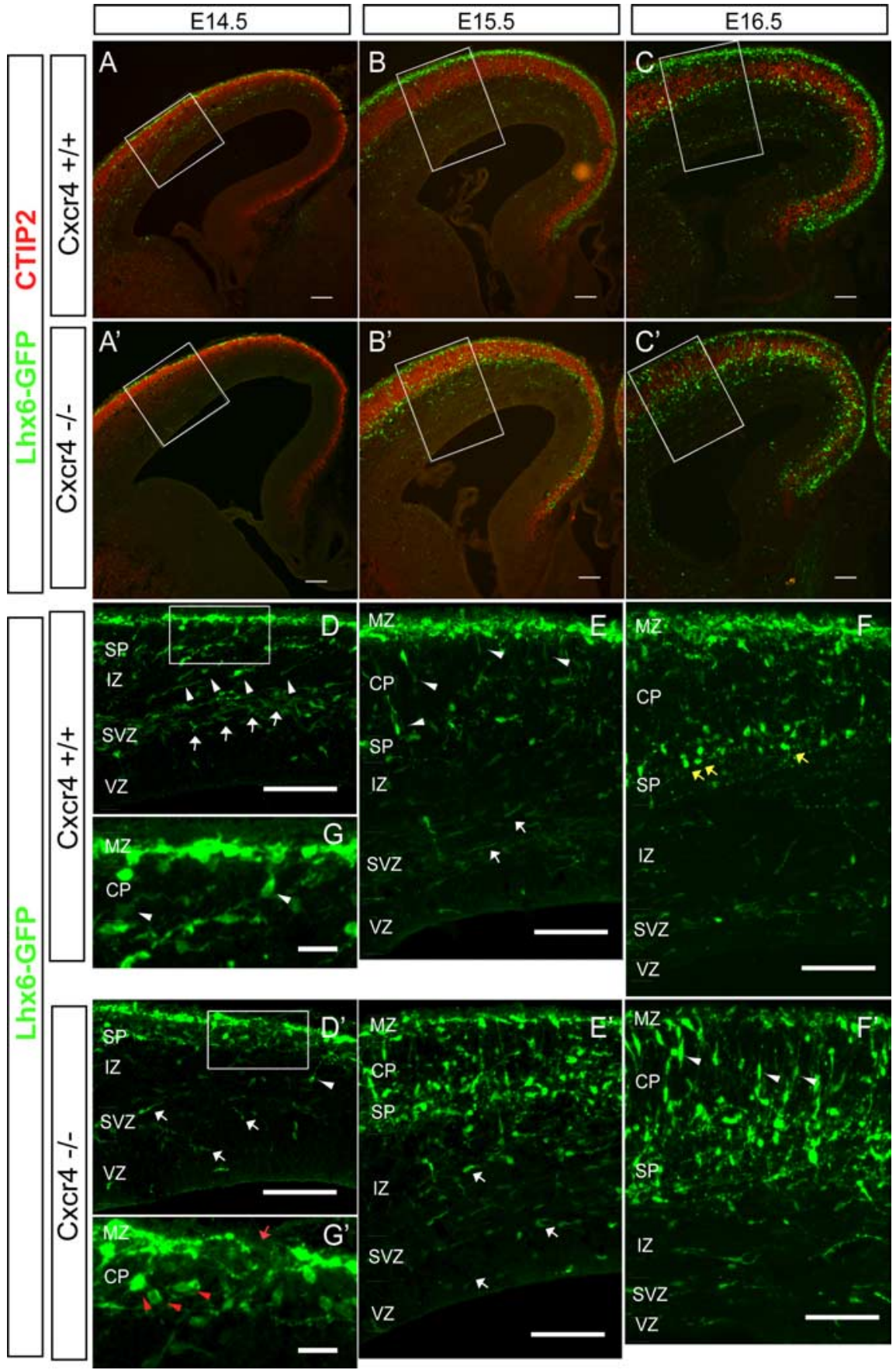

Figure 4. Accumulation of interneurons in the $M Z$ is dependent on $C x c r 4$. Low-power and high-power images (taken from the areas boxed in the low-power images) of $\mathrm{Cxcr}^{+/+}(\boldsymbol{A}-\boldsymbol{C})$ and $\mathrm{Cxcr} 4^{-1-}\left(\boldsymbol{A}^{\prime}-\boldsymbol{C}^{\prime}\right)$ brains combined with a single allele of the Lhx6-GFP transgene from E14.5-E16.5 stained with GFP and CTIP antibodies. A-C demonstrate that over this period the density of GFP + cells in the MZ increases (as we also showed in Fig. 1) in $\mathrm{Cxcr}^{+/+}$mice. By the end of this period, very few cells reside in the cortical plate in $\mathrm{Xxcr}^{+/+}$mice. $\boldsymbol{A}^{\prime}-\mathrm{C}^{\prime}, \ln \mathrm{Cxcr} 4^{-/-}$mice, there is little accumulation of GFP + cells in the $\mathrm{MZ}$, and throughout this period, there are numerous cells in the cortical plate and also scattered throughout the cortical wall. $\mathbf{D}-\mathbf{G}$, Higher-magnification images (taken from the boxed areas in $\boldsymbol{A}-\boldsymbol{D})$ in $\mathrm{CxCr}{ }^{+/+}$allow more detailed analysis over this developmental window. At E14.5 (D, G), the MZ and SVZ (white arrows) streams are distinct, and cells between these in the IZ and the cortical plate have morphologies consistent with migration from one stream to the other (white arrowheads). At E15.5 (E), this trend continues, but there is continued accumulation of GFP + cells in the MZ. At E16.5 $(\boldsymbol{F})$, the MZ is now several GFP + cells thick, and a distinct, new layer of GFP + cells in the subplate that do not have migratory morphology are now prominent (yellow arrows). $\boldsymbol{D}^{\prime}-\boldsymbol{G}^{\prime}$, Higher-magnification images (taken from the boxed areas in $\left.\boldsymbol{A}^{\prime}-\boldsymbol{D}^{\prime}\right)$ in $\left(\mathrm{xcr} 4^{-1-}\right.$ show that at E14.5 $\left(\boldsymbol{D}^{\prime}, \mathbf{G}^{\prime}\right)$ there are gaps in the MZ ( $\boldsymbol{G}^{\prime}$, red arrow) and very few migratory appearing cells in the SVZ ( $\boldsymbol{D}^{\prime}$, white arrows). In addition, the

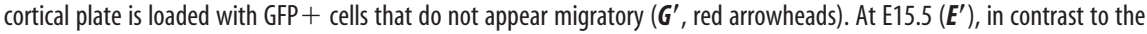
controls, the MZ fails to accumulate GFP + cells, and the subplate and cortical plate are crowded with cells. This trend continues at E16.5 $(\boldsymbol{F})$, with cells in the cortical plate beginning to prematurely adopt radial migratory morphologies $\left(\boldsymbol{F}^{\prime}\right.$, white arrowheads). (P, Cortical plate; SP, subplate.
MZ. However, only a few days earlier, interneuron accumulation in the MZ apparently requires these cells to migrate toward Cxcl12 expressed in the meninges, and this is Cxcr4 dependent. These observations raise the question of whether the timing of accumulation in and then radial migration away from the MZ are controlled by responsiveness to Cxcl12. To examine this, we removed Cxcr4 function after many of the interneurons had already arrived in the $\mathrm{MZ}$ using a conditional (floxed) Cxcr4 allele (Nie et al., 2004) and tamoxifeninduced Cre recombination under the control of a ubiquitously expressed chicken $\beta$-actin promoter (Hayashi and McMahon, 2002). We postulated that removal of Cxcr4 from the cells already in the MZ should accelerate their exit from the MZ. We compared interneuron location in control versus conditional mutant embryos at E19.5 using two interneuron markers (Lhx6 or GAD ISH). Whereas the control cortex shows that many interneurons are in both the MZ and cortical plate (Fig. 5A, B, arrows indicate the MZ), the Cxcr4 mutants (induced at $\sim$ E15.5) had far fewer interneurons in the MZ (Fig. $5 A^{\prime}, B^{\prime}$, arrows). Taking these data with our previous results provides evidence that interneurons accumulate and remain in the $\mathrm{MZ}$ under the control of Cxcr4 signaling and that loss of Cxcr4 signaling from cells in the MZ is sufficient to cause cells to prematurely invade the cortical plate.

\section{Cxcr 4 cell-autonomously regulates} tangential dispersion and lamination of cortical interneurons

Cxcr4 is expressed in developing cortical interneurons and Cajal-Retzius interneurons. Thus, the constitutive and tamoxifen-induced Cxcr4 mutants alter both cell types. To establish whether the observed phenotypes are based on the cellautonomous functions of Cxcr4 in the interneurons, we selectively removed Cxcr4 in the cortical interneurons using Cre expression regulated by the Dlx5/6 intergenic enhancer (Monory et al., 2006). To identify the recombined cells, we used the Cre reporter Z/EG line (Novak et al., 2000). We define mice with the genotype $\mathrm{Z} / \mathrm{EG}^{\mathrm{Tg} /+}$; Dlx $5 / 6 \mathrm{Cre}^{\mathrm{Tg} /+} ; \mathrm{Cxcr} 4^{\mathrm{flox} /-}$ as conditional Dlx5/6 mutants (Dlx5/6-cKO henceforth), whereas animals with the genotype $\mathrm{Z} / \mathrm{EG}^{\mathrm{Tg} /+} ; \mathrm{Dlx} 5 / 6 \mathrm{Cre}^{\mathrm{Tg} /+} ; \mathrm{Cxcr} 4^{\text {flox } /+}$ are used as controls.

Analysis of interneuron distribution at E16.5 in Dlx5/6-cKO shows that most of the mutant $(\mathrm{GFP}+)$ cells were present in the cortical plate rather than accumulated in the MZ (Fig. $6 A, B$, red arrowheads), and 
SVZ (Fig. 6A, $B$, white arrowheads). Moreover, many fewer GFP + cells reach the medial cortex (Fig. 6A, $B$, arrows) than in the constitutive Cxcr4-null mutants (Fig. 4). Because both terminal deoxynucleotidyl transferase-mediated biotinylated UTP nick end labeling and activated caspase staining at a variety of ages in both the null and conditional mutants fail to demonstrate increased numbers of dying cells (data not shown), we believe that the reduced number of interneurons reaching the medial wall by E16.5 is attributable to a primary migration defect rather than accelerated cell death. This is also consistent with our observations of focal excess collections of interneurons at the lateral edge of the neocortex in null mutants (Fig. $3 B$ ), where we suspect some of the excess interneurons collect during prenatal life and thus fail to migrate into the cortex. Thus, mice with conditional loss of Cxcr4 in the cortical interneurons phenocopy the interneuron defects of the constitutive Cxcr4null mutants at prenatal stages (Fig. 4), establishing that the migration phenotype is cell autonomous. Because loss of Cxcr4 function in Cajal-Retzius cells is known to disrupt their development and positioning in the MZ (Borrell and Marín, 2006; Paredes et al., 2006) and these cells could have potential secondary effects on interneurons, the demonstration that the interneuron positioning defects are cell autonomous is quite important.

\section{Postnatal analysis of interneurons lacking Cxcr4}

Cxcr4 constitutive null mutants do not survive postnatally, preventing the analysis of interneuron phenotypes in the maturing and adult cortex. However, Dlx5/6-cKO mutants show normal viability, allowing us to address whether the disruption of interneuron migratory streams will lead to abnormal distribution of interneurons in the cortex. As at E16.5, P8, and P14, Dlx5/6-cKO animals also show reduced interneuron number in the medial cortex (Fig. 6C, $D, E^{\prime}, F^{\prime}$, dashed ovals) and hippocampus (data not shown). Quantitation of GFP + cells in three regions of the cortex (cingulate cortex, motor cortex, and somatosensory cortex) at P14, revealed reductions in GFP+ interneurons: significant differences in interneuron number between mutants and controls that are more severe the more medially this is examined: cingulate cortex is decreased 35\%; motor cortex, 15\%; and somatosensory cortex, 15\% (Fig. 6G) $(n=6)$. Because cortical thickness and neocortical lamination (in both embryonic null and early postnatal cKO mice) appear normal in these mice (data not shown), direct comparison of neuronal number in standard boxes is an appropriate measure of interneuron density in cortical areas.

Next, we investigated the laminar distribution of Cxcr4 mutant interneurons in the cortical wall. To address this, we introduced the Lhx6-GFP transgene into the Dlx5/6-cKO background $\left(\mathrm{Dlx} 5 / 6 \mathrm{Cre}^{\mathrm{Tg} /+} ; \mathrm{Cxcr} 4^{\text {flox/- }}\right.$ ) and the control background (Dlx5/ $\left.6 \mathrm{Cre}^{\mathrm{Tg} /+} ; \mathrm{Cxcr}^{\text {flox/+ }}\right)$. At P14 in the control cortex, most Lhx6$\mathrm{GFP}+$ cells are found in layers IV-VI with a lighter sprinkling of $\mathrm{GFP}+$ cells in more superficial layers (Fig. 7A); we grouped these in three layers (just above each of the dotted lines in Fig. $7 A$ ). In the Dlx5/6-cKO animals, whereas most Lhx6-GFP + cells are still located in the deeper layers of the cortex, there are clear defects in the laminar allocation GFP+ cells. In layer IV, there are domains devoid of GFP + cells (Fig. 7B, arrowheads) and layer V has unusual cell clusters (Fig. $7 B$, arrows). Next, we assessed the distribution of interneurons expressing the GAD1GFP transgene (Oliva et al., 2000). This transgene labels a more restricted group of cells than the Lhx6-GFP transgenic line. In the control animals, GAD1GFP + cells are exclusively localized in the superficial area (layers II-IV) of somatosensory cortex with fairly even distribution (Oliva et al., 2000; Yabut et al., 2007) (Fig. 7C). In contrast, Dlx5/6-cKO mice have domains without labeled cells and other areas with clusters of cells (Fig. 7D, arrowheads and arrows, respectively). Of note, however, the lack of GAD1GFP+ cells in deep cortical layers is not affected by the Cxcr4 mutation (Fig. $7 D)$.

Next, we analyzed the distribution of calretinin and nNOS, which label interneurons with a bias in the upper and lower cortical layers, respectively (Pla et al., 2006). Although most calreti$\operatorname{nin}+$ cells are appropriately located in superficial layers in the Dlx5/6-cKOs (Fig. 7E,F), there are ectopic clusters of calretinin + cells in deeper layers (Fig. $7 F$, dotted oval), similar to what we observed with Lhx6-GFP+ and GAD1GFP+ cells. nNOS+ cells show a relatively compact stripe in layer VI in the control animals (Fig. $7 G$ ), whereas they are more scattered in the Dlx5/ 6-cKO animals with some straying into more superficial zones (Fig. $7 \mathrm{H}$, arrows). We also analyzed the distribution of calbindin-, parvalbumin-, neuropeptide Y-, and somatostatinexpressing interneurons in the Dlx5/6-cKO animals (supplemental Fig. 3, available at www.jneurosci.org as supplemental material). There were no clear defects in the distribution of these classes of cells in the radial dimension of the cortex, but because the normal distribution of these classes of interneurons tends to be rather scattered across multiple cortical layers, subtle changes 

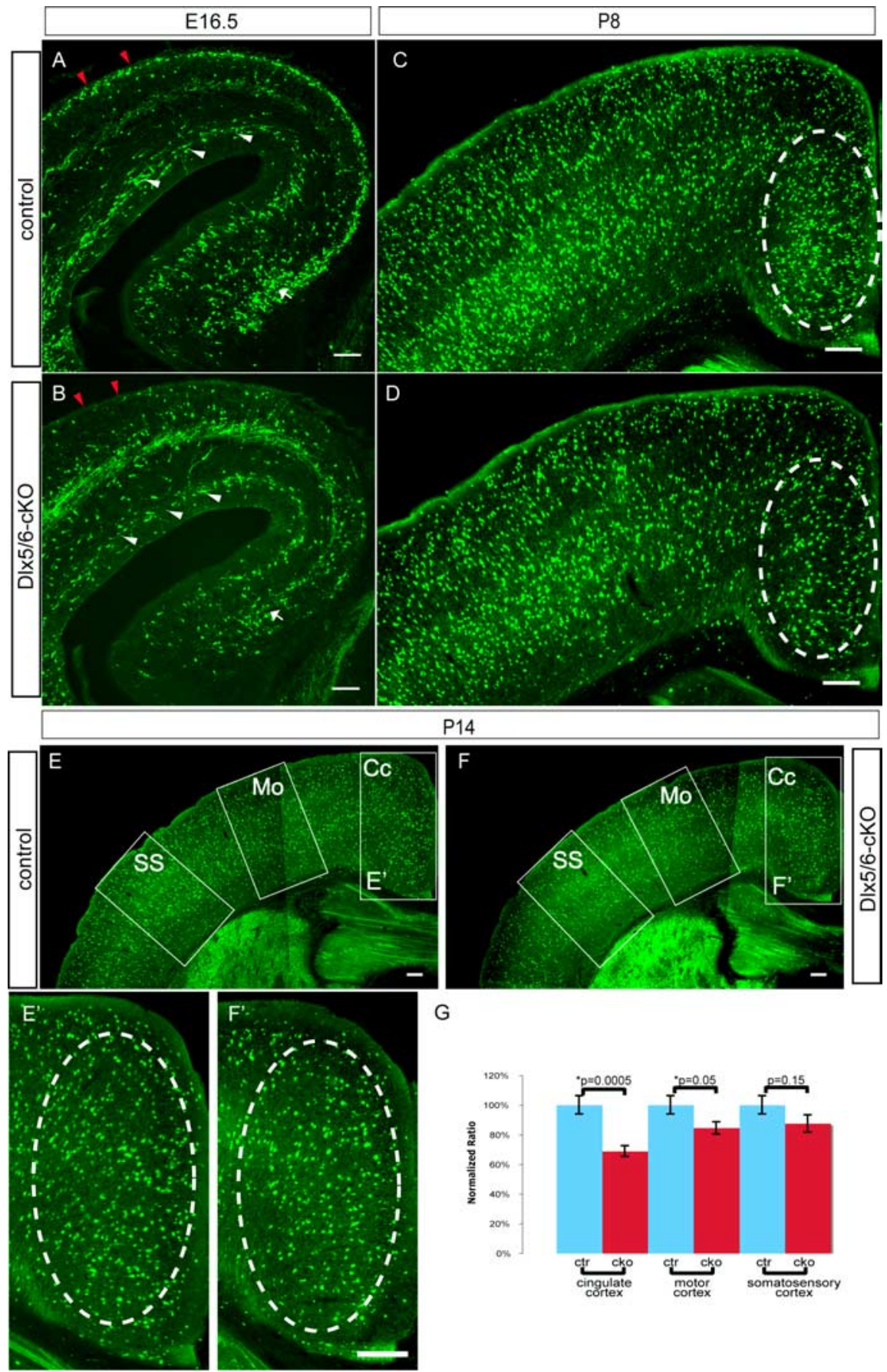

G
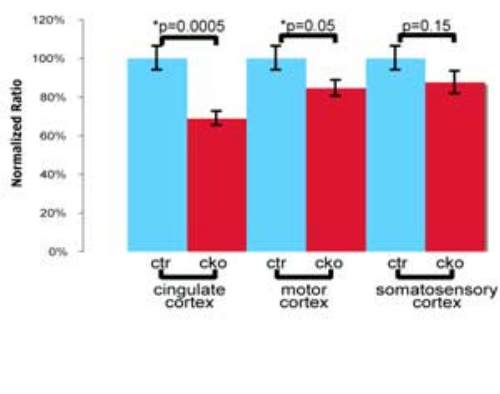

Figure 6. Conditional Cxcr4 mutants have regional interneuron distribution defects. $A-F$, Dlx $5 / 6 C \mathrm{Cre}^{\mathrm{Tg} /++} ; \mathrm{CxCr}^{\mathrm{flox} /+} ; \mathrm{Z} / \mathrm{EG} \mathrm{tg} /+$ (controls) $(A, C, E)$ and Dlx5/6Cre ${ }^{\mathrm{Tg} /+} ; \mathrm{CXCr}^{\mathrm{flox} /-} ; \mathrm{Z} / \mathrm{EG}{ }^{\mathrm{tg} /+}$ (Dlx5/6-CKO) $(\boldsymbol{B}, \boldsymbol{D}, \boldsymbol{F})$ mice are compared at three ages (E16.5, P8, and P14). The distribution of the GFP + cells after staining GFP antibody staining is shown in the coronal sections from animals atE16.5 $(\boldsymbol{A}, \boldsymbol{B}), \mathrm{P} 8(\boldsymbol{C}$, $\boldsymbol{D})$, and P14 $\left(\boldsymbol{E}, \boldsymbol{F}, \boldsymbol{E}^{\prime}, \boldsymbol{F}^{\prime}\right)$. AtE16.5, GFP + cells have accumulated in the MZ in the control mice (A, red arrowheads), but in Dlx5/6-CK0 mice the MZ is depleted of GFP + cells ( $\boldsymbol{B}$, red arrowheads), the SVZ stream in the Dlx5/6-cKOs is diminished compared with the controls $(\boldsymbol{A}, \boldsymbol{B}$, white arrowheads), and there are fewer GFP + cells reaching the hippocampus in the mutants than the controls ( $A, B$, white arrow). The number of GFP + cells in the medial cortex is also decreased consistently in the Dlx5/6-CKO mice atE16.5. Atpostnatal stages (P8and P14), Dlx5/6-CKO mice have major reductions in the numbers of medial cortical GFP + cells, compared with the controls (compare areas in dashed ovals in $\boldsymbol{C}, \boldsymbol{D}$, and $\boldsymbol{E}^{\prime}, \boldsymbol{F}^{\prime}$ ). To quantitate the regional deficits in GFP + cell number at P14 (when most interneurons should have settled into their final positions), a standard-sized box was drawn in the cingulate cortex, motor cortex, and somatosensory cortex, and pairs of animals were counted in matched sections. The number of GFP + cells in each box was normalized to the average of the values counted in the appropriate region in control brains. The normalized ratios are graphed (as percentages \pm SEM) in $\mathbf{G}$. Notably, there is significant reduction in the relative numbers of GFP + cells in the Dlx5/6-cK0 cingulate cortex (CC) (35\% decrease compared with control; $p=0.0005)$ and in the motor cortex (Mo) $(15 \%$ drop; $p=0.05)$ with a similar magnitude but more variable (and not significant statistically) decrease in somatosensory cortex (SS) (13\% drop; $p=0.15)$. Thus, Dlx5/6-cK0 mutant mice have a progressive deficit of recombined interneurons as they are examined more medially. Scale bars: $A, B, 100 \mu \mathrm{m} ;\left(-F, 200 \mu \mathrm{m} ; \boldsymbol{E}^{\prime}, \boldsymbol{F}^{\prime}, 250 \mu \mathrm{m}\right.$. like those described above would be almost impossible to detect. However, what is clear is that there is no dramatic, subtypeselective effect on one class of interneurons.

Thus, although major features of interneuron laminar distribution are intact without functioning Cxcr4, despite the disruption of prenatal laminar organization, there are subtle defects in the distributions of specific interneuron subtypes.

\section{Disrupted interneuron dispersion is associated with changes in cortical excitability}

The interneuron distribution defects we observed in Dlx5/6-cKO-Cxcr4 mutant mice imply that one important function of the tangential migratory streams is to ensure efficient distribution of interneurons throughout the cortex and is required for even distribution from lateral to medial. Loss-of-function analysis demonstrates that $\mathrm{Cxcl} 12 / \mathrm{Cxcr} 4$ signaling is required for both of these functions. Interestingly, we also found that excess, ectopic expression of Cxcl12 by electroporation was sufficient to disrupt the distribution of interneurons by trapping cells in the region of the excess attractant ligand expressed in the cortical wall (Fig. 2). To determine the effects of interneuron distribution defects on cortical excitability, we decided to return to this preparation, which has certain advantages over the loss-of-function situation, including high penetrance (we found that Dlx5/ 6 -cre has $\sim 60 \%$ penetrance, and in fact there was no consistent change in inhibitory tone in the cortex of these animals, probably because of reduced penetrance) (data not shown) and our ability to exclude any potential cell-autonomous functions of Cxcr4 on cellular excitability (Guyon and Nahon, 2007). To determine whether ectopic Cxcl12 expression at embryonic stages causes long-lasting interneuron distribution phenotypes, we analyzed animals at P14 after electroporation at E14.5. Using the Lhx6-GFP line as a reporter, animals electroporated with $\mathrm{Cxcl} 12$ in the region that will generate somatosensory cortex showed that GFP+ cell number was increased locally in the electroporated hemisphere compared with the control hemisphere in the same region (Fig. $8 A, A^{\prime}, A^{\prime \prime}$ ). Quantitation of this effect showed that the ratio of GFP + cells was increased to $150 \%$ in the electroporated region (Fig. $8 \mathrm{~B}$ ). We also determined whether this effect led to defects in the ability of Lhx6-GFP+ cells to reach more medial cortical zones by similar quantitation in the cingulate cortex and found that on the electroporated side that 
$\mathrm{GFP}+$ cell number was reduced to $80 \%$ that found in the contralateral, control cingulate cortex (Fig. $8 \mathrm{~B}$ ) (there were also less interneurons that reached the hippocampus) (data not shown). Supporting our findings in the loss-of-function mutants that there is not a major role for $\mathrm{Cxcl} 12$ in regulating the details of laminar distribution of interneurons, we found that careful analysis of the laminar distribution of Lhx6-GFP + cells in the electroporated regions (by doing bin analysis across the cortical wall) showed that the Cxcl12electroporated side had essentially normal layer distribution compared with the control side (no significant difference was found in the distributions using nonparametric tests of statistical significance) (Fig. $8 C$ ). In conclusion, ectopic expression of Cxcl12 is able to increase the number of interneurons locally found in a cortical region and this can lead to interruption of interneuron migration more medially, but it does not change the lamination profile dramatically. We believe that the ectopic Cxcl12 "traps" cells locally until the developmental responsiveness to Cxcl12 diminishes, and then these cells are distributed to laminar positions according to other local cues in the area; thus, the net result is local increases in interneuron density without severe derangement of interneuron laminar distribution.

This manipulation allowed us to ask whether local changes in interneuron density affect local circuitry properties. Our initial expectation was that overall inhibitory tone on the cortical projection neurons around the ectopic Cxcl12 expression site would be increased because interneurons are more concentrated locally. Indeed, we found a significant increase in the frequency of spontaneous IPSCs (sIPSCs) in recordings from layer 4 pyramidal neurons in the Cxcl12-electroporated zone compared with cells in the contralateral hemisphere. Surprisingly, this enhancement was accompanied by a significant decrease in sIPSC amplitude in pyramidal neurons in the electroporated region (Fig. $9 A-C)$. When we examined pyramidal neurons in the region medial to the Cxcl12electroporated region (where local interneuron density is decreased compared with control), the sIPSC frequency was normal but sIPSC amplitude was again significantly smaller compared with the contralateral side (Fig. 9A-C). Our data suggest that local increases in interneuron density (e.g., in the area of ectopic Cxcl12 expression), which cause an increase in sIPSC frequency, may engage homeostatic mechanisms that reduce sIPSC amplitude to normalize net inhibitory tone. This mechanism may fail when interneuron number is significantly decreased (e.g., in the area with
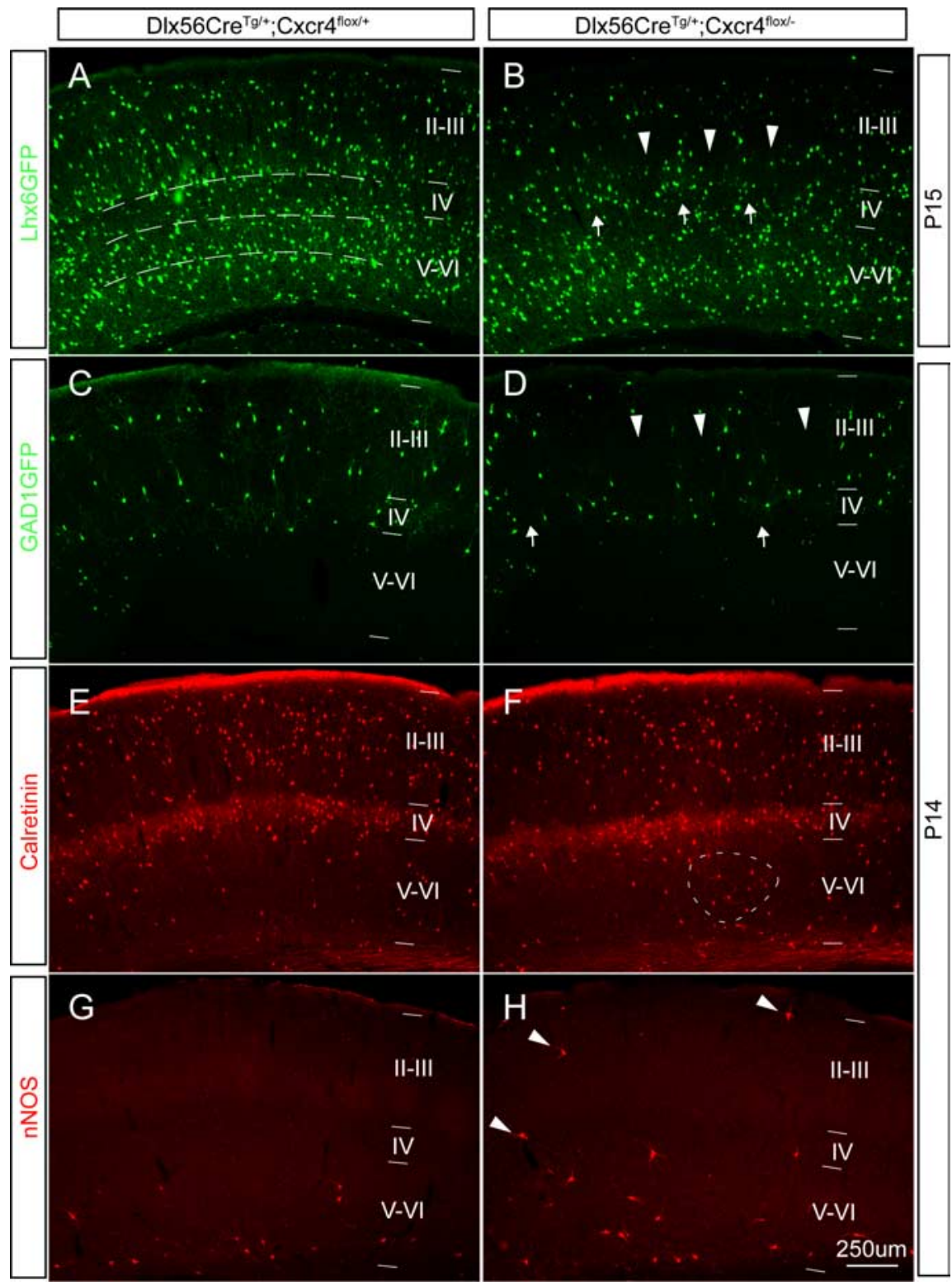

Figure 7. Postnatal conditional $C x c r 4$ mutants have subtle defects in interneuron positioning. $A-D, 0$ ne copy of the Lhx6-GFP BAC transgene or GAD1GFP transgene was crossed into the control background Dlx5/6Cre ${ }^{\mathrm{Tg} /{ }^{+}} ; \mathrm{Cxcr} 4^{\mathrm{flox} /+}(A, C)$ or the conditional mutant background $\mathrm{Dlx} 5 / 6 \mathrm{Cre} \mathrm{g}^{\mathrm{Tg} /+} ; \mathrm{CxCr} 4^{\text {flox/- }}(\boldsymbol{B}, \boldsymbol{D})$. The distribution of GFP + cells is shown in coronal sections from P14 or P15 animals. In both control and mutant animals, Lhx6-GFP+ cells were primarily localized in the deep layers, whereas GAD1-GFP is found mainly in the superficial layers $(\boldsymbol{A}-\boldsymbol{D})$. In the somatosensory cortex of the control animals, Lhx6-GFP + cells showed three relatively distinct laminar concentrations from layer VI to IV, (indicated by the dotted lines in $\boldsymbol{A}$ ). However, in DIx5/6-CK0 mutants, the Lhx6-GFP + cells are distributed as clusters in layer V, and there are bare patches lacking labeled cells in layer IV ( $\boldsymbol{B}$, arrows and arrowheads). Similarly, GAD1-GFP + cells are distributed quite evenly in the superficial cortex of controls $(\boldsymbol{C})$, but there are again bare patches seen in the D1×5/6-cK0 mutants ( $\boldsymbol{D}$, arrowheads) and some areas of clustering ( $\boldsymbol{D}$, arrows). The interneuron subtype markers calretinin and nNOS also are useful to marker particular layer distributions in controls $(\boldsymbol{E}, \boldsymbol{G})$ and Dlx5/6-cK0 mutants $(\boldsymbol{F}, \boldsymbol{H})$. Most calretinin + cells are localized in superficial region in both controls and Dlx5/6-cK0 mutants, but the smaller fraction of calretinin + cells in deeper regions is more evenly distributed in the controls $(\boldsymbol{E})$, than in the Dlx5/6-cK0 mutants, which have areas of clustered, labeled cells ( $\boldsymbol{F}$, dotted oval area). nNOS + cells are primarily found in layer VI in both controls and Dlx5/6-cK0 mutants, but there is a very reproducible finding of small numbers of nNOS + interneurons straying into more superficial positions in the Dlx5/6-cK0 mutants ( $\boldsymbol{H}$, arrowheads). Scale bar, $250 \mu \mathrm{m}$.

reduced interneuron number more medial to the ectopic $\mathrm{Cxcl} 12$ expression). These results demonstrate that a local change in interneuron density functionally alters inhibitory circuitry.

\section{Discussion}

Consistent with the previous studies of others (Stumm et al., 2003; Tiveron et al., 2006), we show that Cxcl12 is a chemoattrac- 

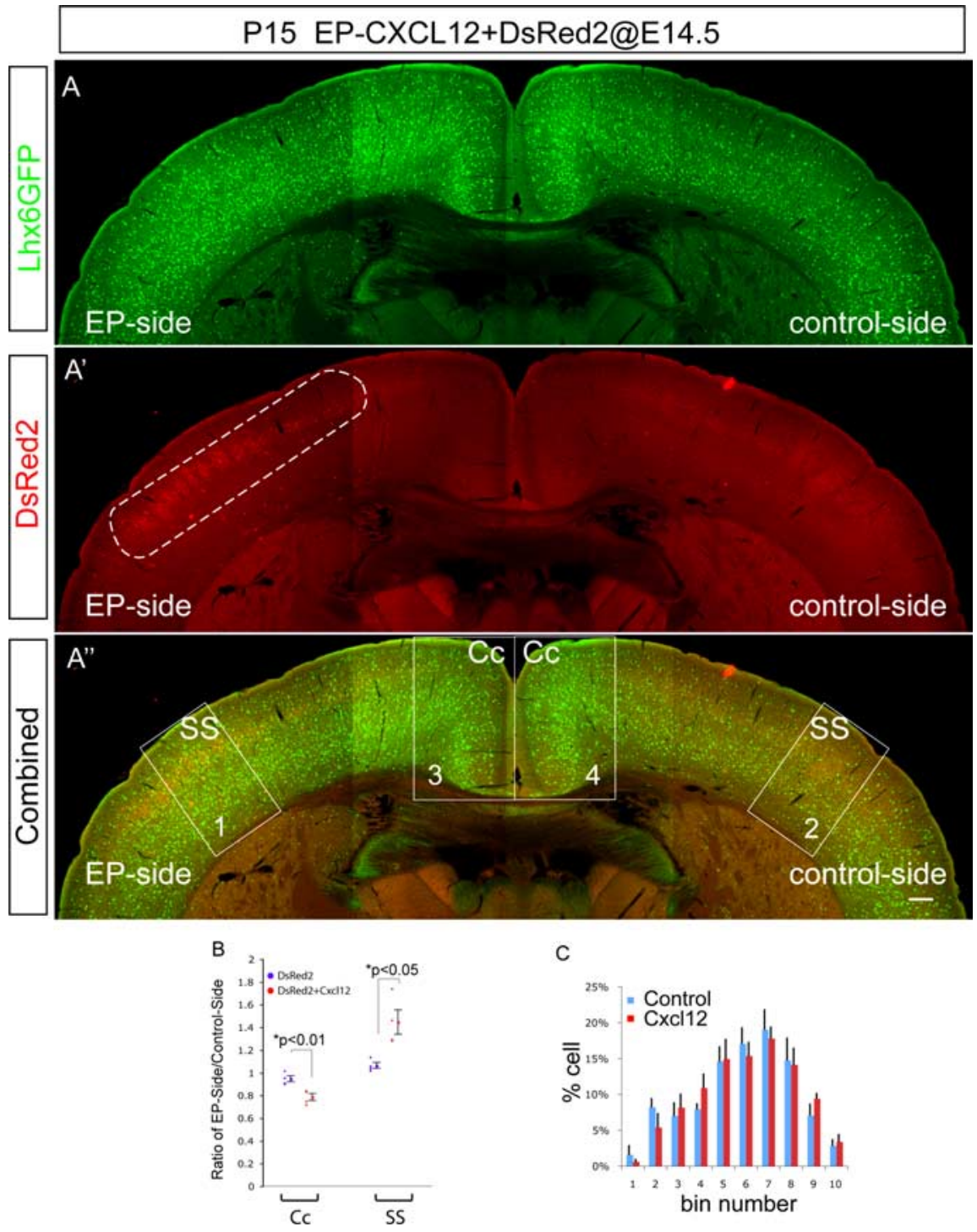

C

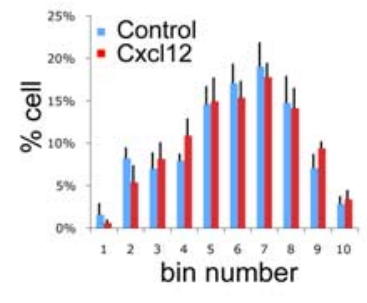

Figure 8. Ectopic $\left(x c 112\right.$ causes long-lasting alterations in regional interneuron distribution. $A, A^{\prime}$, and $\boldsymbol{A}^{\prime \prime}$ show an example of a P15 animal electroporated at E14.5 in utero intraventricularly with pCAG-CxCl12 and pCAG-DsRed2 into the somatosensory cortex on the left (see dotted oval in $\boldsymbol{A}^{\prime}$, which outlines the area expressing DsRed2). In the electroporated region, it is clear that there is a local excess of GFP + cells and also fewer GFP + cells more medially on the electroporated side. Scale bar, $500 \mu \mathrm{m}$. $\boldsymbol{B}$, Uniformly sized boxes were placed in the somatosensory and cingulate cortex on the electroporated side and the contralateral side $(\boldsymbol{A})$. The numbers of Lhx6-GFP + cells were counted in the box on the electroporated side and the contralateral side in each animal $(n=4)$ and a ratio generated as follows: number on electroporated side/number on contralateral side. Data were collected at P15 for the Lhx6-GFP + animals electroporated at E14.5 with DsRed2 alone, or together with Cxcl12 targeted to the somatosensory cortex. These data are graphed and show that there is $\sim 50 \%$ increase in the local number of interneurons in the electroporated somatosensory cortex. In addition, there is an $18 \%$ decrease in the normal number of interneurons in the more medial cingulate cortex. This indicates that interneurons destined for more medial cortical areas were "trapped" en route. Error bar indicates SEM. C, To determine whether local excess in Cxcl12 caused disruption of laminar distribution of interneurons, we split the somatosensory counting boxes into deciles and counted the number of labeled cells in each decile and compared the percentage of the total that this made up between contralateral control and Cxcl12-overexpressing cortex. We used the $\chi^{2}$ test to determine whether there is a statistical difference between the distributions across the cortex and found no significant difference; the error bars are presented as a visual aid to demonstrate the consistency of the binning approach and were not used in determining the statistical significance. Error bar indicates SEM. EP, Electroporated; (c, cingulate cortex; SS, somatosensory cortex.

tant for interneurons, attracting them to form migratory streams. In addition, we show that exit from the streams accompanies loss of $\mathrm{Cxcl} 12$ responsiveness and that timed loss of Cxcr4 function leads to premature stream exit. In addition, we show that interneuron selective loss of Cxcr4 function leads to regional and laminar interneuron distribution defects and that similar distribu- tion defects can have important developmental effects on development of cortical excitability.

Previous studies demonstrated that the meningeal expression of $\mathrm{Cxcl} 12$ regulates Cajal-Retzius cell positioning (Stumm et al., 2003; Borrell and Marín, 2006; Paredes et al., 2006) and maintenance of laminar position of Cajal-Retzius cells in the MZ (Borrell and Marín, 2006; Paredes et al., 2006). Unlike Cajal-Retzius cells, interneurons are apparently only transiently dependent on Cxcl12 to attract and maintain them in the MZ. The stage-dependent responsiveness of interneurons to $\mathrm{Cxcl} 12$ is reminiscent of the situation in the cerebellum where granule cell precursors require Cxcl12/Cxcr4 action to maintain their superficial position in the external granule cell layer adjacent to the meninges ( $\mathrm{Ma}$ et al., 1998; Zou et al., 1998; Reiss et al., 2002; Zhu et al., 2002). Cerebellar granule cells are thought to lose their responsiveness to Cxcl12 as they differentiate and radially migrate through the Purkinje cell layer to the internal granule cell layer (Zhu et al., 2004); however, no previous studies have established that this transient responsiveness to Cxcl12 is present in vivo. Thus, we demonstrate for the first time that neurons in situ have developmentally lost their responsiveness to $\mathrm{Cxcl} 12$, and furthermore, using the conditional Cxcr4 mutants we showed that timed deletion of the $\mathrm{Cxcl} 12$ receptor causes interneurons to immediately exit the MZ. The molecular mechanism whereby interneurons or cerebellar granule cells lose their responsiveness to Cxcl12 in vivo is unknown, but in the cerebellum the termination of $\mathrm{Cxcl} 12$ attractiveness in vitro is associated with reverse signaling through EphrinB1 and a mostly uncharacterized feedback system to terminate Cxcr4 signaling (Lu et al., 2001); however, the developmental roles of this mechanism in vivo remain unexplored.

This reiterated mechanism, whereby Cxcl12 expressed by the meninges attracts migrating neurons to the pial surface of the neural tube, may be a commonly used mechanism to allow rapid long-range migration of certain neuronal classes to form either a temporary or permanent superficial cellular layer. Our study indicates that one functional consequence of this type of developmental organization is to ensure efficient tangential dispersion of these neurons over large territories, perhaps because of motogenic effects of Cxcl12 (O. Marín, personal communication).

\section{Why have interneuron migratory streams?}

The organization of interneurons into tangential migratory streams is a cardinal feature of cortical interneuron development 
A

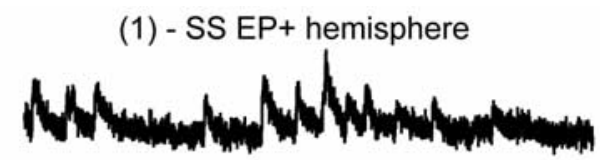

(2) - SS non-EP hemisphere
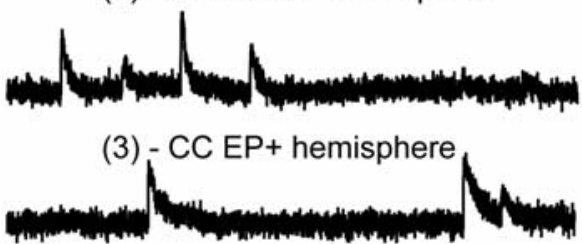

(4) - CC non-EP hemisphere

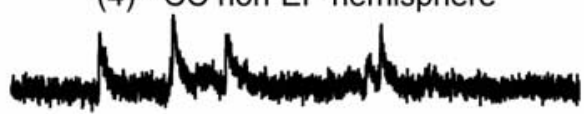

$20 \mathrm{pA} L \frac{}{200 \mathrm{~ms}}$

B

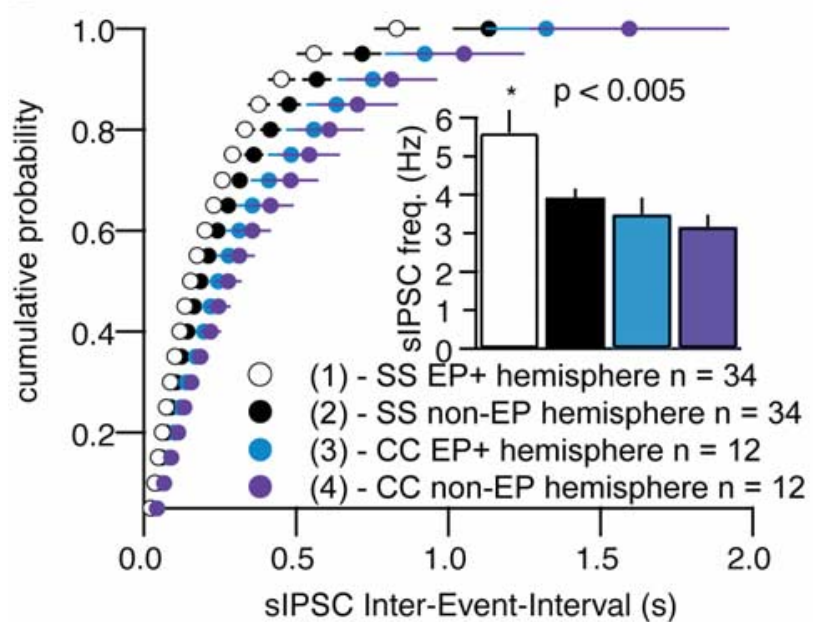

C

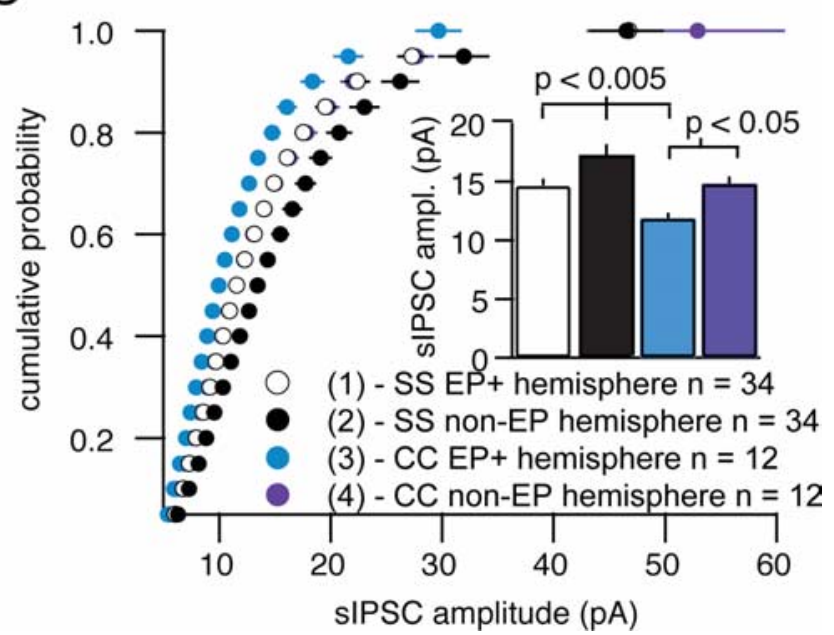

Figure 9. Alterations in regional interneuron distribution alter inhibitory circuitry. A-C, Interneuron accumulation mediated by in utero electroporation of $\mathrm{CxCl} 12$ into the somatosensory cortex increases the frequency but decreases the amplitude of the spontaneous IPSCS recorded from the layer 4 pyramidal neurons on the electroporated side. $A$, Representative traces from layer 4 pyramidal cell recordings from the four regions in which data were collected (SS, somatosensory cortex; (CC, cingulate cortex). The numbering of the white boxes in $A^{\prime \prime}$ from Figure 8 corresponds to the number of each trace in $\boldsymbol{A}$ and to indicate the location of the cells that were recorded in $\boldsymbol{B}$ and $\boldsymbol{C}$. $\boldsymbol{B}$, Cumulative distribution of SIPSC interevent intervals from and there are a variety of signals that regulate this process (Metin et al., 2006). Steps that have been proposed include repulsion from the ganglionic eminences by an as-yet-unidentified factor (Marín et al., 2003), avoidance of the striatum by semaphorinmediated repulsion (Marín et al., 2001), and attraction to the cortex by neuregulins (Flames et al., 2004), GDNF (glial cell linederived neurotrophic factor) (Pozas and Ibanez, 2005), and HGF (hepatocyte growth factor) (Powell et al., 2001), but it has remained unclear why this complex framework is required.

Here, we demonstrated the cell-autonomous function of Cxcr4 in regulating the regional and laminar prenatal and postnatal distribution of cortical interneurons. It was originally proposed that maintaining careful organization of interneurons during migration would be crucial to the final laminar positioning of interneurons (Stumm et al., 2003). However, our data indicate that laminar organization during migration is unlikely to be a major contributing factor to final laminar positioning. We did find clear but subtle defects in the postnatal laminar organization of interneurons in interneuron-selective conditional Cxcr4 mutants, but these are far less severe than would have been expected if laminar organization during migration were a dominant regulator of final laminar fate. This is also consistent with studies transplanting cells isolated from the ganglionic eminences directly into the cortex, avoiding the entire tangential migratory route, showing that these cells still appear to integrate fairly normally into the host cortex (Xu et al., 2004).

An additional function of interneuron migratory streams might be to sequester interneurons above and below the cortical plate to regulate the timing and nature of interactions between interneurons and projection neurons. The cortical plate may be the source of cues that regulate interneuron maturation; the pace of interneuron maturation may control the development of interneuron processes and thereby their connectivity (Cobos et al., 2007). Furthermore, the streams may partially insulate the immature projection neurons from the interneurons, and thereby reduce their exposure to GABA. Developmental modulation in the chloride reversal potential, switching the early excitatory role of GABA to its later inhibitory action, is controlled by the KCC2 potassium-chloride pump in projection neurons (Rivera et al., 1999; Fiumelli et al., 2005), and GABA itself is sufficient to drive this switch (Ganguly et al., 2001). In addition, premature expression of KCC2 accelerates onset of this switch and has significant consequences for the long-term maturation of projection neurons (Cancedda et al., 2007).

The major developmental consequence of disruption of Cxcl12/Cxcr4 signaling during interneuron migration, either by misexpression of Cxcl12 in the lateral neocortex, or by Cxcr4 loss of function selectively in interneurons, are defects in interneuron regional distribution. This results in undersupply of interneurons, especially to medial cortical structures more distant from the sites of origin laterally. Thus, the main function of Cxcl12/ Cxcr4 signaling is to ensure appropriate dispersion and targeting of interneurons to all regions of cortex, but future studies may indicate that the migratory streams have additional roles in controlling aspects of the overall tempo of cortical development that will have potent consequences for later cortical plasticity and processing.

pyramidal cells on the electroporated side compared with cells in the corresponding contralateral regions. C, Cumulative distribution of SIPSC amplitudes from pyramidal cells on the electroporated side compared with cells in the corresponding contralateral regions. All errors bars are SEM. EP, Electroporated. 
Because we were able to reproducibly generate mice with regional defects in cortical interneuron distribution by ectopic Cxcl12 expression, we examined the physiological consequences of having either too many or too few interneurons within cortical regions. We found regions with excess interneurons $(\sim 150 \%$ of the normal number) had an increase in IPSC frequency, indicating a larger number of inhibitory synapses per cortical projection neuron. This was accompanied by a decrease in IPSC amplitude, which we believe reflects a form of homeostatic compensation to maintain the appropriate balance of inhibitory tone. However, in regions with reduced interneurons ( $\sim 80 \%$ of normal), IPSC amplitudes were dramatically decreased without a compensatory increase in IPSC frequency. This indicates that, in regions with reduced numbers of interneurons, individual projection neurons have the appropriate numbers of inhibitory synapses, but the reduced IPSC amplitude indicates that the individual inhibitory synapses are of reduced efficiency. We believe that this reflects a failure of full compensation by the reduced number of interneurons, which by being forced to make extra synapses (increased synapses made per local interneuron) are unable to maintain the appropriate efficiency of these synapses. Future studies can now be addressed toward understanding the molecular and structural nature of this homeostatic compensation and why it breaks down when interneuron number is reduced. We hypothesize that the developmental plan of interneuron stream migration is important for ensuring appropriate distribution of interneuron numbers to cortical regions, and it is critical for establishing the normal balance of excitation and inhibition in the cortex.

Thus, focal changes in $\mathrm{Cxcl} 12 / \mathrm{Cxcr} 4$ signaling in the cortex disrupt interneuron dispersion and alter excitatory/inhibitory balance. Of note, focal neonatal ischemic injuries in rodents induce penumbral expression of Cxcl12 (Hill et al., 2004; Imitola et al., 2004; Miller et al., 2005); this could lead to physiological defects similar to what we observed by ectopic Cxcl12 expression. Therefore, it is possible that focal neonatal ischemia in infants could alter interneuron distributions and be a predisposition for epilepsy, cognitive impairments, or sensorimotor deficits.

\section{Final laminar fate of interneurons must be controlled by additional determinants}

If laminar organization during interneuron tangential migration is not a major regulator of final laminar fate, then what does regulate the radial migration of interneurons from the $M Z$ and SVZ/IZ to their appropriate final layers? For many years, it has been known that many interneurons sort into their final layers according to a birthdate gradient, akin to the layered organization of cortical projection neurons (Angevine and Sidman, 1961; Hevner et al., 2004). Interestingly, recent findings have refined this understanding and shown that, although some interneurons do have a birthdate-dependent laminar organization, it may not be regulated in the same way as projection neurons. For example, parvalbumin + interneurons are distributed in an inside-out gradient like projection neurons, whereas calretinin + interneurons are distributed in an outside-in gradient opposite to the organization of projection neurons (Rymar and Sadikot, 2007). Therefore, it appears that interneurons do have a laminar organization dependent on birthdate, but that it is not regulated in the same way as for projection neurons. Also, Reelin signaling, which regulates laminar position of projection neurons, does not appear to autonomously regulate interneuron laminar position (Pla et al., 2006). Thus, future work will need to establish how interneurons decipher where to intercalate within the cortical plate. Recent studies that have begun to comprehensively profile the specific molecular features of particular layers of cortical projection neurons (Arlotta et al., 2005; Sugino et al., 2006; Molyneaux et al., 2007) are likely to reveal candidates for these molecular regulators.

\section{References}

Alifragis P, Liapi A, Parnavelas JG (2004) Lhx6 regulates the migration of cortical interneurons from the ventral telencephalon but does not specify their GABA phenotype. J Neurosci 24:5643-5648.

Ang E, Haydar TF, Gluncic V, Rakic P (2003) Four-dimensional migratory coordinates of GABAergic interneurons in the developing mouse cortex. J Neurosci 23:5805-5815.

Angevine Jr JB, Sidman RL (1961) Autoradiographic study of cell migration during histogenesis of cerebral cortex in the mouse. Nature 192:766-768.

Arlotta P, Molyneaux BJ, Chen J, Inoue J, Kominami R, Macklis JD (2005) Neuronal subtype-specific genes that control corticospinal motor neuron development in vivo. Neuron 45:207-221.

Ayala R, Shu TZ, Tsai LH (2007) Trekking across the brain: the journey of neuronal migration. Cell 128:29-43.

Borrell V, Marín O (2006) Meninges control tangential migration of hemderived Cajal-Retzius cells via CXCL12/CXCR4 signaling. Nat Neurosci 9:1284-1293.

Cancedda L, Fiumelli H, Chen K, Poo MM (2007) Excitatory GABA action is essential for morphological maturation of cortical neurons in vivo. J Neurosci 27:5224-5235.

Cobos I, Long JE, Thwin MT, Rubenstein JL (2006) Cellular patterns of transcription factor expression in developing cortical interneurons. Cereb Cortex 16 [Suppl 1]:i82-i88.

Cobos I, Borello U, Rubenstein JL (2007) Dlx transcription factors promote migration through repression of axon and dendrite growth. Neuron 54:873-888.

Cossart R, Bernard C, Ben-Ari Y (2005) Multiple facets of GABAergic neurons and synapses: multiple fates of GABA signalling in epilepsies. Trends Neurosci 28:108-115.

Daniel D, Rossel M, Seki T, Konig N (2005) Stromal cell-derived factor-1 (SDF-1) expression in embryonic mouse cerebral cortex starts in the intermediate zone close to the pallial-subpallial boundary and extends progressively towards the cortical hem. Gene Expr Patterns 5:317-322.

Fiumelli H, Cancedda L, Poo MM (2005) Modulation of GABAergic transmission by activity via postsynaptic $\mathrm{Ca}^{2+}$-dependent regulation of KCC2 function. Neuron 48:773-786.

Flames N, Long JE, Garratt AN, Fischer TM, Gassmann M, Birchmeier C, Lai C, Rubenstein JLR, Marín O (2004) Short- and long-range attraction of cortical GABAergic interneurons by neuregulin-1. Neuron 44:251-261.

Ganguly K, Schinder AF, Wong ST, Poo M (2001) GABA itself promotes the developmental switch of neuronal GABAergic responses from excitation to inhibition. Cell 105:521-532.

Guyon A, Nahon JL (2007) Multiple actions of the chemokine stromal cellderived factor- $1 \alpha$ on neuronal activity. J Mol Endocrinol 38:365-376.

Hayashi S, McMahon AP (2002) Efficient recombination in diverse tissues by a tamoxifen-inducible form of Cre: a tool for temporally regulated gene activation/inactivation in the mouse. Dev Biol 244:305-318.

Hensch TK (2005) Critical period plasticity in local cortical circuits. Nat Rev Neurosci 6:877-888.

Hevner RF (2007) Layer-specific markers as probes for neuron type identity in human neocortex and malformations of cortical development. J Neuropathol Exp Neurol 66:101-109.

Hevner RF, Daza RA, Englund C, Kohtz J, Fink A (2004) Postnatal shifts of interneuron position in the neocortex of normal and reeler mice: evidence for inward radial migration. Neuroscience 124:605-618.

Hill WD, Hess DC, Martin-Studdard A, Carothers JJ, Zheng J, Hale D, Maeda M, Fagan SC, Carroll JE, Conway SJ (2004) SDF-1 (CXCL12) is upregulated in the ischemic penumbra following stroke: association with bone marrow cell homing to injury. J Neuropathol Exp Neurol 63:84-96.

Imitola J, Raddassi K, Park KI, Mueller FJ, Nieto M, Teng YD, Frenkel D, Li J, Sidman RL, Walsh CA, Snyder EY, Khoury SJ (2004) Directed migration of neural stem cells to sites of CNS injury by the stromal cell-derived factor 1alpha/CXC chemokine receptor 4 pathway. Proc Natl Acad Sci USA 101:18117-18122.

Liodis P, Denaxa M, Grigoriou M, Akufo-Addo C, Yanagawa Y, Pachnis V (2007) Lhx6 activity is required for the normal migration and specification of cortical interneuron subtypes. J Neurosci 27:3078-3089. 
Lu Q, Sun EE, Klein RS, Flanagan JG (2001) Ephrin-B reverse signaling is mediated by a novel PDZ-RGS protein and selectively inhibits $G$ proteincoupled chemoattraction. Cell 105:69-79.

Ma Q, Jones D, Borghesani PR, Segal RA, Nagasawa T, Kishimoto T, Bronson RT, Springer TA (1998) Impaired B-lymphopoiesis, myelopoiesis, and derailed cerebellar neuron migration in CXCR4- and SDF-1-deficient mice. Proc Natl Acad Sci USA 95:9448-9453.

Marín O, Yaron A, Bagri A, Tessier-Lavigne M, Rubenstein JL (2001) Sorting of striatal and cortical interneurons regulated by semaphorinneuropilin interactions. Science 293:872-875.

Marín O, Plump AS, Flames N, Sánchez-Camacho C, Tessier-Lavigne M, Rubenstein JL (2003) Directional guidance of interneuron migration to the cerebral cortex relies on subcortical Slit1/2-independent repulsion and cortical attraction. Development 130:1889-1901.

Metin C, Baudoin JP, Rakic S, Parnavelas JG (2006) Cell and molecular mechanisms involved in the migration of cortical interneurons. Eur J Neurosci 23:894-900.

Miller JT, Bartley JH, Wimborne HJ, Walker AL, Hess DC, Hill WD, Carroll JE (2005) The neuroblast and angioblast chemotaxic factor SDF-1 (CXCL12) expression is briefly up regulated by reactive astrocytes in brain following neonatal hypoxic-ischemic injury. BMC Neurosci 6:63.

Molyneaux BJ, Arlotta P, Menezes JR, Macklis JD (2007) Neuronal subtype specification in the cerebral cortex. Nat Rev Neurosci 8:427-437.

Monory K, Massa F, Egertova M, Eder M, Blaudzun H, Westenbroek R, Kelsch W, Jacob W, Marsch R, Ekker M, Long J, Rubenstein JL, Goebbels S, Nave KA, During M, Klugmann M, Wolfel B, Dodt HU, Zieglgansberger W, Wotjak CT, et al. (2006) The endocannabinoid system controls key epileptogenic circuits in the hippocampus. Neuron 51:455-466.

Nie Y, Waite J, Brewer F, Sunshine MJ, Littman DR, Zou YR (2004) The role of CXCR4 in maintaining peripheral B cell compartments and humoral immunity. J Exp Med 200:1145-1156.

Novak A, Guo C, Yang W, Nagy A, Lobe CG (2000) Z/EG, a double reporter mouse line that expresses enhanced green fluorescent protein upon Cremediated excision. Genesis 28:147-155.

Oliva Jr AA, Jiang M, Lam T, Smith KL, Swann JW (2000) Novel hippocampal interneuronal subtypes identified using transgenic mice that express green fluorescent protein in GABAergic interneurons. J Neurosci 20:3354-3368.

Paredes MF, Li GN, Berger O, Baraban SC, Pleasure SJ (2006) Stromalderived factor-1 (CXCL12) regulates laminar position of Cajal-Retzius cells in normal and dysplastic brains. J Neurosci 26:9404-9412.

Pla R, Borrell V, Flames N, Marin O (2006) Layer acquisition by cortical GABAergic interneurons is independent of Reelin signaling. J Neurosci 26:6924-6934

Powell EM, Mars WM, Levitt P (2001) Hepatocyte growth factor/scatter factor is a motogen for interneurons migrating from the ventral to dorsal telencephalon. Neuron 30:79-89.

Pozas E, Ibanez CF (2005) GDNF and GFR alpha 1 promote differentiation and tangential migration of cortical GABAergic neurons. Neuron 45:701-713.

Reiss K, Mentlein R, Sievers J, Hartmann D (2002) Stromal cell-derived factor 1 is secreted by meningeal cells and acts as chemotactic factor on neuronal stem cells of the cerebellar external granular layer. Neuroscience 115:295-305.

Rivera C, Voipio J, Payne JA, Ruusuvuori E, Lahtinen H, Lamsa K, Pirvola U, Saarma M, Kaila K (1999) The $\mathrm{K}^{+} / \mathrm{Cl}^{-}$co-transporter KCC2 renders GABA hyperpolarizing during neuronal maturation. Nature 397:251-255.

Rymar VV, Sadikot AF (2007) Laminar fate of cortical GABAergic interneurons is dependent on both birthdate and phenotype. J Comp Neurol 501:369-380.

Stumm R, Kolodziej A, Schulz S, Kohtz JD, Höllt V (2007) Patterns of SDF-1 alpha and SDF-1 gamma mRNAs, migration pathways, and phenotypes of CXCR4-expressing neurons in the developing rat telencephalon. J Comp Neurol 502:382-399.

Stumm RK, Zhou C, Ara T, Lazarini F, Dubois-Dalcq M, Nagasawa T, Höllt V, Schulz S (2003) CXCR4 regulates interneuron migration in the developing neocortex. J Neurosci 23:5123-5130.

Sugino K, Hempel CM, Miller MN, Hattox AM, Shapiro P, Wu C, Huang ZJ, Nelson SB (2006) Molecular taxonomy of major neuronal classes in the adult mouse forebrain. Nat Neurosci 9:99-107.

Tanaka D, Nakaya Y, Yanagawa Y, Obata K, Murakami F (2003) Multimodal tangential migration of neocortical GABAergic neurons independent of GPI-anchored proteins. Development 130:5803-5813.

Tissir F, Wang CE, Goffinet AM (2004) Expression of the chemokine receptor Cxcr4 mRNA during mouse brain development. Dev Brain Res 149:63-71.

Tiveron MC, Rossel M, Moepps B, Zhang YL, Seidenfaden R, Favor J, König $\mathrm{N}$, Cremer H (2006) Molecular interaction between projection neuron precursors and invading interneurons via stromal-derived factor 1 (CXCL12)/CXCR4 signaling in the cortical subventricular zone/intermediate zone. J Neurosci 26:13273-13278.

Wonders C, Anderson SA (2005) Cortical interneurons and their origins. Neuroscientist 11:199-205.

Wulff P, Wisden W (2005) Dissecting neural circuitry by combining genetics and pharmacology. Trends Neurosci 28:44-50.

Xu Q, Cobos I, De la Cruz E, Rubenstein JL, Anderson SA (2004) Origins of cortical interneuron subtypes. J Neurosci 24:2612-2622.

Yabut O, Renfro A, Niu S, Swann JW, Marin O, D’Arcangelo G (2007) Abnormal laminar position and dendrite development of interneurons in the reeler forebrain. Brain Res 1140:75-83.

Yokota Y, Gashghaei HT, Han C, Watson H, Campbell KJ, Anton ES (2007) Radial glial dependent and independent dynamics of interneuronal migration in the developing cerebral cortex. PLoS ONE 2:e794.

Zhu Y, Yu T, Zhang XC, Nagasawa T, Wu JY, Rao Y (2002) Role of the chemokine SDF-1 as the meningeal attractant for embryonic cerebellar neurons. Nat Neurosci 5:719-720.

Zhu Y, Yu T, Rao Y (2004) Temporal regulation of cerebellar EGL migration through a switch in cellular responsiveness to the meninges. Dev Biol 267:153-164.

Zou YR, Kottmann AH, Kuroda M, Taniuchi I, Littman DR (1998) Function of the chemokine receptor CXCR4 in haematopoiesis and in cerebellar development. Nature 393:595-599. 